\title{
The role of high-pressure coolant in the wear characteristics of WC-Co tools during the cutting of Ti-6Al-4V
}

\author{
Pietro Stolf $^{1 *}$, Jose Mario Paiva ${ }^{1,2}$, Yassmin Seid Ahmed ${ }^{1,3}$, Jose Luis Endrino $^{4}$, Saurav Goel ${ }^{4}$ \\ and Stephen Clarence Veldhuis ${ }^{1}$ \\ ${ }^{1}$ McMaster Manufacturing Research Institute (MMRI), Department of Mechanical Engineering, McMaster University, 1280 \\ Main Street West, Hamilton, ON L8S4L7, Canada; stolfp@mcmaster.ca; paivaji@mcmaster.ca; Seidahmy@mcmaster.ca; \\ veldhu@mcmaster.ca \\ ${ }^{2}$ Mechanical Engineering Graduate Program - PPGEM, Pontificia Universidade Católica do Paraná, Curitiba - 80215901, \\ Brazil \\ ${ }^{3}$ Production Engineering Department, Alexandria University, Alexandria, 21544, Egypt \\ ${ }^{4}$ School of Aerospace, Transport and Manufacturing, Cranfield University, College Rd, Bedfordshire MK43 0AL, UK; \\ j.l.endrino@cranfield.ac.uk; saurav.goel@cranfield.ac.uk \\ *Correspondence: stolfp@mcmaster.ca; Tel.: +1-905-818-0031
}

\begin{abstract}
Aeronautic applications have been making use of titanium alloys for decades. Ti-6Al-4V is one of the most commonly applied alloys, and although its mechanical properties warrant its acceptance for many applications, the machinability of this alloy remains a challenge. So far, the most successful technique in facilitating this alloy's machining has been the application of HighPressure Coolant Supply (HPC) on account of its influence on the tribological aspects of the cutting operation. On that premise, this work employs experimental and computational resources to advance the current understanding of the wear mechanism in terms of the tool-chip contact conditions and establish a correlation between coolant pressure, cutting speed, tool life, cutting forces, and chip formation when machining Ti-6Al-4V with HPC supply. Results showed that HPC plays a role in the reduction of tool-chip temperature profiles and contact stresses, positivelly impacting tool flank wear, oxidation levels and chip formation, also improving chip breakability. Keywords:

Tool wear, Titanium, High-Pressure Coolant, tribology, FEA, chip formation.
\end{abstract}




\section{Introduction}

Ti-6Al-4V is the titanium alloy with the broadest range of applications, accounting for 45$65 \%$ of the world's titanium consumption [1]. It is widely applied in the aerospace industry, mainly due to its exceptional specific strength and unmatched mechanical properties [2]].

Due to its low thermal conductivity and high chemical reactivity, Ti-6Al-4V is classified as a difficult-to-cut material [3,4]. Titanium machining leads to significantly increased temperatures at the tool/chip interface, even at lower cutting speeds [5]. Furthermore, the Ti and $\mathrm{Al}$ (it is made of) present a strong affinity to most tool materials [6], imposing an even bigger challenge to the processing of this alloy. In order to mitigate such effects, a common approach would be the reduction of cutting speed, which directly reduces temperatures in the cutting zone [7]. This would however, adversely affect the production, as low material removal rate (MRR) would increase the demand-supply gaps, making products containing Ti alloys less viable.

Previous researchers have generally made use of coated cutting tools to interfere with the severe interactions taking place during the titanium machining process $[8,9]$. However, results were not satisfactory when machining Ti and its alloys, as most available coatings are composed of $\mathrm{Ti}$ and $\mathrm{Al}$, which would react with the workpiece material. An alternative to the use of tool coatings is the application of cutting fluids to reduce thermal and mechanical loads, especially when working at higher cutting speeds, where heat becomes the main cause for accelerated tool wear [3]. However, conventional coolant supplies do not ensure targeted fluid delivery in the cutting zone and thus, coolant application by traditional means does not achieve significant efficiency [10]. Through careful setup, cutting fluids can be directed towards the primary, secondary, and tertiary shear deformation zones. The secondary shear deformation zone, located at the tool/chip interface, presents a combination of high shear and normal stresses, parallel to the long tool/workpiece contact surface [7]. It consists of the most heat intensive region during the cutting process, requiring substantial cooling action. On that premise, flood coolant supplies can not adequately access the secondary shear deformation zone, due to the barrier imposed by the severe tool/chip contact conditions, resulting in intensive heat generation. To address this issue, different cooling strategies have been employed to improve machining performance of titanium alloys. Cryogenic cooling was deemed a suitable alternative to conventional flood coolant supply when working with low thermal conductivity alloys [11,12]. Conversely, the use of cryogenic cooling significantly increases workpiece material hardness, negatively impacting mechanical 
loads and promoting accelerated tool wear rates in the case of Ti alloys [10]. This added to its high operational costs and impact on dimensional control, makes cryogenic machining unfit for these industrial applications. Experiments are reported on the use of Minimum Quantity Lubrication (MQL) for the machining of titanium alloys. The application of MQL was also not proven effective [11-14], since its cooling capabilities are limited when dealing with the high levels of heat imposed by the cutting process.

A newer alternative emerging in this direction is the use of High-Pressure Coolant (HPC), which is capable of providing a relatively low cost alternative that is able to address most of the aforementioned issues $[10,15]$. Moreover, the added benefit of using HPC for the machining of Ti alloys is an improved sub-surface integrity [10]. Figure 1 illustrates some of the key benefits provided by the application of HPC to the rake face of the cutting tool. That includes the reduction in chip curl radius, promotion of chip breakability, and heat dissipation from the tool-chip interface [7]. The shorter TCCL (Tool-Chip Contact Length) contributes to lower diffusion wear rates and consequently prolongs the lifespan of the cutting tool [7].

As the issue being investigated in this paper i.e. HPC assisted cutting of Ti6Al4V is topical and is in infancy stages of research, many aspects such as chip formation, tool-chip contact conditions and thermal phenomena when machining titanium are hitherto unexplored. Therefore, this work aims to develop a better understanding of the of the wear mechanism, the chip formation, contact conditions and mechanical/thermal aspects of the titanium machining process when employing high pressure coolant supplies at different pressures, combined with multiple sets of cutting parameters. Adding to the experimental findings, computational resources were utilised to study the temperature and stress profiles. The analysis of the collected data allowed for establishing a correlation between: coolant pressure, cutting speed, tool life, cutting forces, wear mechanisms and chip formation. 


\section{Materials and methods}

\subsection{Finite Element Analysis}

The finite element analysis (FEA) is an essential tool for the evaluation of cutting conditions, such as temperature/stress profiles within the cutting zone. The primary difficulty in the FEA of metal cutting is capturing the severe plastic deformation of the metal, which results in extreme tribological conditions at the tool-workpiece interface [16].

Modeling of metal machining for turning requires a fundamental understanding of the deformation conditions in the relevant deformation zones, strain rates, as well as the frictional conditions at the tool-workpiece interface. The cutting temperature/stress profile is critical for understanding and controlling the machining process [17].

The numerical analyses present in this work were carried ou on a commercial FEA code (Thirdwave's Advantedge CAE software). Advantage employs a Lagrangian approach combined with adaptive remeshing capabilities [18]. This formulation is responsible for addressing the nonlinearities caused by the high levels of plastic deformation, strain rates and inherent resolution issues arising during the turning process.

The constitutive model derived from the Cuitino and Ortiz stress update method is employed for the flow stress calculations (eq. 1), where $\alpha$ ) refers to the strain hardening, $\Theta(\mathrm{T})$ to the thermal softening and $\Gamma(\dot{\alpha}) \alpha \dot{\alpha} \quad T$ refer to rate sensitivity, equivalent plastic strain, plastic strain rate, and temperature, respectively [19].

$$
\sigma(\alpha, \dot{\alpha}, T)=g(\alpha) \Theta(\mathrm{T}) \Gamma(\dot{\alpha})
$$

Furthermore, the power law (eq. 2) is used to describe strain hardening and rate sensitivity, where reference values for strain and strain rates are denoted by $\alpha_{0}$ and $\alpha_{0}$, respectively.

$$
g(\alpha)=\left(\sigma_{0} 1+\frac{\alpha}{\alpha_{0}}\right)^{\frac{1}{\bar{N}}}, \Gamma(\dot{\alpha})=\left(1+\frac{\dot{\alpha}}{\dot{\alpha}_{0}}\right)^{\frac{1}{\mathrm{M}}}
$$

A fifth order polynomial function is used to determine thermal softening (eq. 3) [19]. 
Adaptive remeshing capabilities enable the model to account for the element deformations that are intrinsic to the Lagrangian method. Deformations were being constantly monitored, anytime a certain tolerance is met, refinement/coarsening algorithms are applied in order to regenerate the mesh in the best way possible [19]. The biggest advantage of this approach is the ability to resolve different scaled regions for different moments in time, thus, elements present in a plastic deformation intensive region will be resized to accurately reproduce such effects. Likewise, inactive areas will be coarsened, so computational resources are spared and better deployed [19]. For our case, the cutting tool was modeled as a rigid body and Coulomb's friction was applied to the relevant zones.

In modelling the pressure effect of coolant, the velocity of the jet was inputted to the software. Which was calculated using the jet area based on the nozzle diameter, and the flow rate. It is assumed that the flow is uniform and steady after leaving the nozzle and that the speed of the jet is not appreciably reduced after hitting the chip. The pressure exerted by the jet is applied on the chip surface. The heat exchange between the chip and coolant was modeled as convective thermal boundary conditions. Orthogonal (2-dimensional) cutting was employed for simplification matters, as experimental validation attested for the validity of the model, implying a plain strain model that does not account for the load distribution applied by the coolant in the $\mathrm{Z}$ axis, and all data input regarding simulation parameters are displayed in Table 1.

\subsection{Experimental methodology}

The cutting tests were performed on a SC-450 Nakamura-Tome CNC Lathe (Figure 2a). The semi-synthetic, $6 \%$ concentrated, cutting fluid was supplied to the rake face of the commercially available Kennametal CNMG 432 uncoated Tungsten Carbide (WC) grade k turning insert by a ChipBLASTER J8-1000 High Pressure Coolant Supply, through Sandvik's PCLNL 16 4DHP (Figure 2b-c) Coolant-through tool holder.

The ASTM B265 Grade 5 Ti6A14V workpiece (Figure 2b), also known as Ti64 was used for all cutting operations. The workpiece used was of a cylindrical shape measuring approximately $100 \mathrm{~mm}$ in diameter and $250 \mathrm{~mm}$ in length. Material properties, chemical composition, and microstructure provided by the supplier are listed in Table 2 . 
The selected cutting parameters are listed in Table 3. The main idea behind these severe cutting conditions is to accelerate and intensify the wear mechanisms on the uncoated cemented carbide tools. Thus, allowing for a better visualization of the phenomena taking place during the cutting process, as well as the role played by the HPC supply.

Cutting forces were measured by a three component Kistler 9121 tool holder dynamometer (2b), transmitting to a Kistler 5010 amplifier, and recorded using LABVIEW 14.0 during the first 50 meters of cutting length.

As shown in Figure 3, a thermocouple was positioned close to the rake face of the cutting tool. The insertion was made by EDM (Electrical Discharge Machining), allowing for the acquisition of peak temperature measurements $[7,20]$. This setup was performed exclusively for modeling validation. Unaltered cutting tools were employed in the actual cutting tests.

Chips were collected at the end of the first cutting step. Therefore, tool/chip contact conditions would not be affected by the geometry changes imposed by tool wear. The maximum flank wear criterion was set to 300 microns or 2500 meters of cutting length, whichever occurred first. Flank wear measurements were taken for 100-150-meter steps, as well as optical microscopy images (KEYENCE VHX-5000) of the worn inserts' rake and flank surfaces. In order to provide a better understanding of the tool/chip contact behavior during the machining process, a Tescan VEGA2 Scanning Electron Microscope (SEM) was employed to acquire high magnification images of surface topography of chips and worn cutting inserts. Additionally, orientation maps were obtained by Electron Backscattered Diffraction (EBSD) using a JEOL JSM-7000F Scanning Electron Microscope. Moreover, white light interferometry was introduced by an Alicona Infinite Focus optical microscope for 3D surface measurements of the worn inserts and collected chips. A high resolution Nikon Eclipse LV100 optical microscope was used for the microstructural analysis of the chips' cross sections. Prior to imaging, samples were cold mounted, polished and etched by swabbing a cotton ball rinsed in a solution of $\mathrm{HF}+\mathrm{HNO} 3$ for 10 seconds.

Vickers microhardness tests on the cross section measurements of the collected chips were performed by a Matsuzawa MMT-X7A micro Vickers hardness tester with a diamond quadrangular pyramid indenter at $50 \mathrm{gf}$ for 10 seconds. 


\section{Results and Discussion}

\subsection{FEA results}

As shown in Figure 4, simulation results present slightly higher temperature values in comparison to the experimental data but keeping the same trend. This difference in temperature could be attributed the thermo couple being positioned few millimetres away from the tool-chip interface [7] (Figure 3). In addition, a slight decrease in peak temperature is presented when comparing both conditions at $150 \mathrm{~m} / \mathrm{min}$ (Figure $4 \mathrm{a}, \mathrm{b}$ ), which can be attributed to the reduced contact pressure and consequent attenuated friction conditions occasioned by the HPC jet. While overall temperature changes are not so significant, Figure 4 (d-f) reveals a considerable difference in peak temperatures on the chips. This data indicates that a higher amount of heat is being directed towards the chip, which is a highly desirable outcome when machining difficult-to-cut alloys, since the excessive heat present at the rake face of the cutting tool will facilitate the diffusion process, resulting in accelerated crater wear and a reduction in tool life. As crater wear progresses, material is being removed from the insert, thus weakening the tool's cutting edge, ultimately leading to its catastrophic failure.

As shown in Figure $4(\mathrm{e}, \mathrm{f})$, the additional momentum provided by the HPC jet results in some regions of concentrated strain, where chips are most susceptible to breaking. However, the same cannot be said for the flood condition presented in Figure 4-d, where the chip curls at its natural unobstructed radius, implying an undesirable continuous chip formation that might lead to poor surface finish, excessive heat accumulation and ultimately, premature tool failure.

A notable reduction in TCCL (tool-chip contact length) for the two HPC scenarios is presented in Figure 5. The changes were $\sim 50 \%$ for the $150 \mathrm{~m} / \mathrm{min}$ (Figure $5-\mathrm{b}$ ) and $250 \mathrm{~m} / \mathrm{min}$ (Figure 5-c) HPC conditions. The stress concentration exhibits a direct correlation with the length of the contact region. Additionally, a reduction in contact pressure is visible for the two HPC scenarios, which reflects in a less intensive overall stress profile. High contact loads are some of the main facilitators of the adhesion process, once the adhesive bond's strength is proportional to the pressure being applied to it. That said, the eventual tearing apart of the welded workpiece material will cause what is known as plucking, causing damage that is similar to the diffusion process. 
The higher chip temperatures presented in Figure 4, combined with the lower contact stresses in Figure 5, indicate an increase in the portion of heat generated by plastic deformation over the heat provided by friction for the HPC conditions.

\subsection{Tool life}

Figure 6 presents a direct tool life comparison between all the tested conditions. The graph shows the maximum flank wear achieved at the same cutting length (as displayed on the graph) for each set of cutting parameters proposed in Table 3. The length is determined by the point of failure (when flank wear exceeds the pre-established end of life criteria) for the worst performing coolant pressure at a specific cutting speed.

When analysing the results presented in Figure 6, a trend can be noticed in terms of maximum flank wear vs. coolant pressure. Higher coolant pressures have a positive impact on wear rates throughout the cutting process, which can be attributed to the reduced thermal and mechanical loads acting on the tool, as seen in Figures 4 and 5. Hoier et al. [21] highlighted similar behavior when machining Inconel 718 with HPC supply. This was attributed to the cobalt binder present in the insert's composition being subject to thermal softening, making it easier to be removed in the abrasion process. The temperature profiles shown in Figure 4 support that idea. For the flood condition, heat is being dissipated into the cutting tool instead of being carried away by the chips. Furthermore, it also explains the higher flank wear rates measured for the cutting speeds of $200 \mathrm{~m} / \mathrm{min}$ and $250 \mathrm{~m} / \mathrm{min}$.

As shown in Figure 7, when cutting at the lowest speed of $150 \mathrm{~m} / \mathrm{min}$ with the addition of HPC, inserts were able to reach 2500 meters of cutting length without surpassing the preestablished end of life criteria (300 $\mu$ m flank wear). In fact, when looking at the wear curves shown in Figure 7, flank wear was less than half of what was obtained for the flood benchmark condition. Similar results were obtained at the highest cutting speed of $250 \mathrm{~m} / \mathrm{min}$, where the best tool life results were achieved for the same pressure of 1000 psi.

Cutting forces (Figure 8) are also significantly lower for the HPC when compared to the benchmark. A reduction in the order of $40 \%$ at $150 \mathrm{~m} / \mathrm{min}$ can be observed, which can be attributed to a more efficient chip evacuation, thus requiring less power from the machine tool to advance the cut. A correlation can also be established between the stress profiles seen in Figure 5 and the cutting forces in Figure 8, once the compressive loads acting against the cutting movement are 
visibly higher for the flood condition. On that basis, cutting forces are mainly dependant on the area of the shear planes [7,22]. Hence, the reduction in TCCL has a direct impact on the values observed for the two HPC scenarios. These results agree to what was found by previous research performed by Jagtap et al. [23]. On that premise, further analyses were narrowed down to the benchmark flood condition and these two sets of parameters: $150 \mathrm{~m} / \mathrm{min}$ at $1000 \mathrm{psi}$ and $250 \mathrm{~m} / \mathrm{min}$ at $1000 \mathrm{psi}$. With the focus on pointing out the factors leading to this notable improvement in tool wear and cutting forces.

\subsection{Tool wear modes and mechanisms}

Secondary Electron SEM images were taken from the worn tools' rake and flank faces in order to identify the main wear modes taking place during the cutting process. When analysing Figure 9 (a-c), the dominance of adhesion and diffusion over other wear mechanisms becomes evident, what leads to the formation of Built-up edge (BUE) and crater wear modes. The images also show a positive influence of cutting speed on the BUE formation [7,22,24]. In Figure 9-a, the extension of crater wear is about double the size of what is seen at the same cutting speed for the HPC condition (Figure 9-b), supporting a shorter contact length. The presence of oxidation wear is only expressive for the flood condition (Figure 9-a). Oxidation is normally found near the end of the contact region, being a result of the reaction between oxygen and the tool binder [7]. On that premise, the less intense sliding contact pressure, present in that area, allows for the access of oxygen; thus, enabling the reaction. Furthermore, abrasion marks were noticed to be more pronounced at the high-speed condition presented in Figure 9-c, resulting in lower tool life. Abrasion is visible since there is not a substantial volume of material adhered to the rake face of the insert.

Further volumetric analysis showed that for both HPC (Figure 10) scenarios the amount of adhered material, represented by $\mathrm{Vp}$ (Volume of peaks above reference), is in fact reduced (Figure $10 \mathrm{~b}, \mathrm{c})$ when compared to the flood condition. It also displays the lower adhesion at a higher cutting speed (Figure 10-c). In contrast to that, Vv (Volume of valleys below reference), representing the volume of removed tool material, is noticeably higher at this speed. Note that this number accounts not only for crater wear, but also for the abrasion that is very pronounced at 250 $\mathrm{m} / \mathrm{min}$. 
There are three main contributors to the presented wear mechanisms: contact, load and affinity. In this way, HPC promotes the separation between the chip and the rake face of the cutting tool, thus reducing the contact length as well as the mechanical loads acting on that region, which can be proven by the simulation results shown in Figures 4 and 5 .

\subsection{Cutting chips analysis}

Secondary electron images of the chips undersurface and shear bands were taken to attest for the influence of HPC on chip morphology. By looking at the undersurface of the studied chips (Figure 11-a), some inclusions are noticed to be more frequent at the HPC scenarios, which is possibly an indicator of the sticky nature of contact for those conditions. To strengthen that hypothesis, as previously observed in Figure 9, a longer sliding contact region was detected for the benchmark flood scenario, which means reduced contact pressure at the tool / chip interface.

Images shown in Figure 11-b have revealed that segmentation is present for all three of the tested conditions. In general, segmented chips are common when machining alloys with high hardness and low thermal conductivity, such as titanium [25]. It is also considered, for some particular situations, a desirable outcome for cutting force reduction and enhanced chip evacuation [26]. Furthermore, the segmentation edges are smoother when working with the high-pressure coolant supply, meaning that the shear band formation process is facilitated by its application, revealing one of the possible reasons for the force reductions presented in Figure 8. Tool wear will also impact the chip formation process, as stated by Dargusch et al. [25], segmentation and deformation of chips will be significantly impacted as machining progresses.

Based on the obtained experimental results for chip formation and tool wear mechanisms, the schematic diagram presented in Figure 12 attempts to illustrate the changes occurring at the tool/chip contact area when applying HPC. In Figure 12-a, the normal stress decreases exponentially along the contact region and is inversely proportional to the chip's sliding velocity, becoming maximum at the tool tip and minimum at the point where chip loses contact with the cutting tool. The normal stress and sliding velocity profiles combined, contribute to the definition of the so-called sticking and sliding regions, the first one being characterized by high levels of contact pressure and significantly low chip sliding velocity, and the second one where pressure is reduced, thus allowing the chip to flow at a higher speed. These contact conditions are altered once HPC is introduced. As presented in Figure 12-b, once contact pressure (normal stress) is reduced 
to a certain level, by the application of high-pressure coolant, the chip immediately loses contact with the tool's rake face, not allowing for the sliding interaction. On that basis, a direct correlation can be drawn from the tools analyzed in Figure 9, where oxidation was not significant for the HPC conditions; therefore, suggesting a substantially shorter low pressure contact area, and the chips presented in Figure 11, where the presence of inclusions on the collected samples, characterizes a process of "sticky" nature.

To investigate the role of HPC as well as the cutting speeds on the shear bands, the chip cross sections were analyzed using EBSD, and the acquired data is presented in Figure 13. As shown, the resulting orientation maps of the regions taken from the chips in Figure 13 (a, c, e) are shown in Figure 13 (b, d, f), respectively. It can be observed that the grains are more elongated at higher cutting speeds (Figure 13-f) when compared to lower ones (Figure 13-d). The same can be stated when comparing HPC to flood conditions, because of the severe plastic deformation caused by HPC application. Here, the shear bands formed by flood coolant (Figure 13-b) have equiaxed grains $(\sim 1 \mu \mathrm{m})$ compared to a mixture of equiaxed $(\sim 7 \mu \mathrm{m})$ and highly elongated grains in the case of machining with HPC (Figure 13 (d, f)).

Figure 14 presents the pole Figure maps of the chips obtained at different cutting conditions. As shown, most of the grains in the chips obtained with flood condition, posses a Goss $\left\{\begin{array}{lll}1 & 1 & 0\end{array}\right\}$ texture (Figure 14-a) while the majority of the grains obtained with HPC possess an orientation close to the Cube $\left\{\begin{array}{lll}1 & 0 & 0\end{array}\right\}$ (001) texture as shown in Figure 14-b and 14-c. Seid Ahmed et al. [27] concluded that in general, the Cube texture has higher plasticity compared to the Goss texture. The main reason for this is that the Cube texture contains more slip systems, helping it to deform quickly during the machining process [28]. Thus, the chips obtained with HPC (Figures 14-b and 14-c) show highly elongated grains compared with very equiaxed grains of the chips obtained with flood condition.

The micro hardness values in Table 4 are in agreement with the EBSD data presented in Figures 13 and 14, attesting for the strain hardening resultant of the high deformation levels imposed by the application of HPC. This becomes more evident for the areas close to the tool-chip contact region, where the variation in hardness is noticeably higher. The severe plastic deformation imposed by HPC causes the chips to strain harden, and once they are fragilized, their breakability is improved. 


\section{Conclusions}

The experiments performed showed that the tool-chip contact conditions are affected significantly by the application of HPC, indicating that its influence goes beyond chip control. It also allowed for the establishment of a correlation between: coolant pressure, cutting speed, tool life, cutting forces, wear mechanisms, and chip formation. Resulting in the following contributions:

1. Modeling and experiments show a tool temperature reduction for the HPC process, whereas for these same conditions, peak chip temperatures are increased. This data combined with the less severe tool-chip interactions demonstrated in the stress profiles, indicates an increase in the portion of heat generated by plastic deformation over the heat provided by friction for the HPC conditions. In addition, it also results in reduced diffusion and adhesion rates.

2. Coolant pressure and maximum flank wear are inversely proportional to each other, indicating an influence of the heat directed towards the flank face of the cutting tool on the abrasion process. This fact could be explained by the thermal softening of the cobalt binder present in the insert's composition.

3. Oxidation wear is noticeably less extensive when employing HPC supplies, which suggests an interruption of tool-chip contact right after the end of the sticking zone.

4. Chip formation is facilitated by HPC. Improved chip evacuation allied to the lower compressive loads at the rake face of the cutting insert, caused a reduction in cutting forces as well as the formation of smoother shear bands, indicating a more stable process.

5. The strain hardening of the chips collected for the HPC process have a positive impact on their breakability. This fact is supported by the EBSD results, which attested for the presence of highly deformed grain textures.

\section{Acknowledgements}

The authors gratefully acknowledge that this research was supported by Natural Sciences and Engineering Research Council of Canada (NSERC) under the CANRIMT Strategic Research Network Grant NETGP 479639-15. 


\section{References}

[1] Lütjerin G, Williams JC. Titanium. Berlin, Heidelberg: Springer; 2007. doi:10.1007/978-3540-73036-1.

[2] Veiga C., Devim J. P., Loureiro A. J. R. Properties and applications of titanium alloys: a brief review. Rev Adv Mater Sci 2012;32:133-48.

[3] Ezugwu EO, Batista Da Silva R, Falco Sales W, Rocha Machado A. Overview of the Machining of Titanium Alloys. Encycl. Sustain. Technol., vol. 2, Elsevier; 2017, p. 487506. doi:10.1016/B978-0-12-409548-9.10216-7.

[4] Ezugwu EO. Key improvements in the machining of difficult-to-cut aerospace superalloys. Int J Mach Tools Manuf 2005;45:1353-67. doi:10.1016/j.ijmachtools.2005.02.003.

[5] Guo YB, Li W, Jawahir IS. Surface integrity characterization and prediction in machining of hardened and difficult-to-machine alloys: A state-of-art research review and analysis. Mach Sci Technol 2009;13:437-70. doi:10.1080/10910340903454922.

[6] Rosemar B, Machado ÁR, Ezugwu EO, Bonney J, Sales WF. Journal of Materials Processing Technology Tool life and wear mechanisms in high speed machining of Ti $-6 \mathrm{Al}$ - 4V alloy with PCD tools under various coolant pressures 2013;213:1459-64.

[7] Shaw MC. Metal Cutting Principles. New York: Oxford University Press; 2002. doi:10.1016/0025-5408(96)80018-3.

[8] Paiva JM, Shalaby MAM, Chowdhury M, Shuster L, Chertovskikh S, Covelli D, et al. Tribological and Wear Performance of Carbide Tools with TiB2 PVD Coating under 
Varying Machining Conditions of TiAl6V4 Aerospace Alloy. Coatings 2017;7:187. doi:10.3390/coatings7110187.

[9] Chowdhury MSI, Chowdhury S, Yamamoto K, Beake BD, Bose B, Elfizy A, et al. Wear behaviour of coated carbide tools during machining of Ti6Al4V aerospace alloy associated with strong built up edge formation. Surf Coatings Technol 2017;313:319-27. doi:10.1016/j.surfcoat.2017.01.115.

[10] Liu W, Liu Z. High-pressure coolant effect on the surface integrity of machining titanium alloy Ti-6Al-4V: a review. Mater Res Express 2018;5:032001. doi:10.1088/20531591/aab44f.

[11] Suhaimi MA, Yang G-D, Park K-H, Hisam MJ, Sharif S, Kim D-W. Effect of Cryogenic Machining for Titanium Alloy Based on Indirect, Internal and External Spray System. Procedia Manuf 2018;17:158-65. doi:10.1016/j.promfg.2018.10.031.

[12] Park K-H, Yang G-D, Suhaimi MA, Lee DY, Kim T-G, Kim D-W, et al. The effect of cryogenic cooling and minimum quantity lubrication on end milling of titanium alloy Ti6Al-4V. J Mech Sci Technol 2015;29:5121-6. doi:10.1007/s12206-015-1110-1.

[13] Khatri A, Jahan MP. Investigating tool wear mechanisms in machining of Ti-6Al-4V in flood coolant, dry and MQL conditions. Procedia Manuf 2018;26:434-45. doi:10.1016/j.promfg.2018.07.051.

[14] Attanasio A, Gelfi M, Giardini C, Remino C. Minimal quantity lubrication in turning: Effect on tool wear. Wear 2006;260:333-8. doi:10.1016/j.wear.2005.04.024.

[15] Klocke F, Lung D, Cayli T, Döbbeler B, Sangermann H. Evaluation of energy efficiency in 
cutting aerospace materials with high-pressure cooling lubricant supply. Int J Precis Eng Manuf 2014;15:1179-85. doi:10.1007/s12541-014-0454-2.

[16] Vakis AI, Yastrebov VA, Scheibert J, Nicola L, Dini D, Minfray C, et al. Modeling and simulation in tribology across scales: An overview. Tribol Int 2018;125:169-99. doi:10.1016/j.triboint.2018.02.005.

[17] Melkote SN, Grzesik W, Outeiro J, Rech J, Schulze V, Attia H, et al. Advances in material and friction data for modelling of metal machining. CIRP Ann 2017;66:731-54. doi:10.1016/j.cirp.2017.05.002.

[18] Liu C, Goel S, Llavori I, Stolf P, Giusca CL, Zabala A, et al. Benchmarking of several material constitutive models for tribology, wear, and other mechanical deformation simulations of Ti6Al4V. J Mech Behav Biomed Mater 2019;97:126-37. doi:10.1016/j.jmbbm.2019.05.013.

[19] Man X, Ren D, Usui S, Johnson C, Marusich TD. Validation of Finite Element Cutting Force Prediction for End Milling. Procedia CIRP 2012;1:663-8. doi:10.1016/j.procir.2012.05.019.

[20] Komanduri R, Hou Z. A review of the experimental techniques for the measurement of heat and temperatures generated in some manufacturing processes and tribology. Tribol Int 2001;34:653-82. doi:10.1016/S0301-679X(01)00068-8.

[21] Hoier P, Klement U, Tamil Alagan N, Beno T, Wretland A. Flank wear characteristics of WC-Co tools when turning Alloy 718 with high-pressure coolant supply. J Manuf Process 2017;30:116-23. doi:10.1016/j.jmapro.2017.09.017. 
[22] Trent EM. Metal Cutting. London: Butterworths; 1983.

[23] Jagtap KA, Pawade RS. Some Studies on Chip Formation Mechanism in CNC Turning of Biocompatible Co-Cr-Mo Alloy. Procedia Manuf 2018;20:283-9. doi:10.1016/j.promfg.2018.02.042.

[24] Oliaei SNB, Karpat Y. Built-up edge effects on process outputs of titanium alloy micro milling. Precis Eng 2017;49:305-15. doi:10.1016/j.precisioneng.2017.02.019.

[25] Dargusch MS, Sun S, Kim JW, Li T, Trimby P, Cairney J. Effect of tool wear evolution on chip formation during dry machining of Ti-6Al-4V alloy. Int $\mathrm{J}$ Mach Tools Manuf 2018;126:13-7. doi:10.1016/j.ijmachtools.2017.12.003.

[26] Chandra A, Karra P, Bragg A, Wang J, Kim GY. Chip Segmentation in Machining: A Study of Deformation Localization Characteristics in Ti6Al4V. Vol. 1 Process., ASME; 2013. doi:10.1115/MSEC2013-1070.

[27] Ahmed YS, Paiva JM, Bose B, Veldhuis SC. New observations on built-up edge structures for improving machining performance during the cutting of superduplex stainless steel. Tribol Int 2019;137:212-27. doi:10.1016/j.triboint.2019.04.039.

[28] Nomani J, Pramanik A, Hilditch T, Littlefair G. Stagnation Zone during the Turning of Duplex SAF 2205 Stainless Steels Alloy. Mater Manuf Process 2017. doi:10.1080/10426914.2017.1279289.

\section{List of figures}


Fig. 1. - Graphic representation highlighting the changes in chip formation and contact length between (a) flood/dry and (b) HPC conditions.

Fig. 2. (a) Machine tool, (b) workpiece, dynamometer, tool holder setup and (c) detailed view of tool and coolant-through tool holder.

Fig. 3. Experimental temperature measurement point.

Fig. 4. Temperature measurements for both simulation and experimental conditions, combined with FEA results for chip formation at (a,d) flood $-150 \mathrm{~m} / \mathrm{min}$, (b,e) $1000 \mathrm{psi}-150 \mathrm{~m} / \mathrm{min}$ and (c,f) $1000 \mathrm{psi}-250 \mathrm{~m} / \mathrm{min}$.

Fig. 5. Tool stress profiles and TCCL for (a) flood $-150 \mathrm{~m} / \mathrm{min}$, (b) $1000 \mathrm{psi}-150 \mathrm{~m} / \mathrm{min}$ and (c) $1000 \mathrm{psi}-250 \mathrm{~m} / \mathrm{min}$.

Fig. 6. Flank wear comparison chart + MRR (Material Removal Rates) for all conditions.

Fig. 7. Tool wear progression curves for flood $-150 \mathrm{~m} / \mathrm{min}, 1000 \mathrm{psi}-150 \mathrm{~m} / \mathrm{min}$ and $1000 \mathrm{psi}$ $-250 \mathrm{~m} / \mathrm{min}$.

Fig. 8. Cutting forces for flood $-150 \mathrm{~m} / \mathrm{min}, 1000 \mathrm{psi}-150 \mathrm{~m} / \mathrm{min}$ and $1000 \mathrm{psi}-250 \mathrm{~m} / \mathrm{min}$.

Fig. 9. SEM of worn inserts for (a) flood $-150 \mathrm{~m} / \mathrm{min}$, (b) $1000 \mathrm{psi}-150 \mathrm{~m} / \mathrm{min}$ and (c) 1000 psi $-250 \mathrm{~m} / \mathrm{min}$, indicating the presence of oxidation, crater, BUE and flank wear modes.

Fig. 10. Volumetric analysis of worn tools for (a) flood $-150 \mathrm{~m} / \mathrm{min}$, (b) $1000 \mathrm{psi}-150 \mathrm{~m} / \mathrm{min}$ and (c) $1000 \mathrm{psi}-250 \mathrm{~m} / \mathrm{min}$, indicating the volumes of adhered and removed material from the cutting inserts.

Fig. 11. SEM of (a) chip undersurfaces and (b) shear bands.

Fig. 12. Tribological conditions along the rake face of the insert for (a) dry / flood, and (b) highpressure coolant conditions.

Fig. 13. Chips cross-sections and EBSD orientation maps for (a,b) flood $-150 \mathrm{~m} / \mathrm{min},(\mathrm{c}, \mathrm{d}) 1000$ $\mathrm{psi}-150 \mathrm{~m} / \mathrm{min}$ and $(\mathrm{e}, \mathrm{f}) 1000 \mathrm{psi}-250 \mathrm{~m} / \mathrm{min}$.

Fig. 14. EBSD pole figures for (a) flood $-150 \mathrm{~m} / \mathrm{min}$, (b) $1000 \mathrm{psi}-150 \mathrm{~m} / \mathrm{min}$ and (c) $1000 \mathrm{psi}$ $-250 \mathrm{~m} / \mathrm{min}$. 


\section{List of tables}

Table 1. Simulation parameters for all the tested conditions.

Table 2. Chemical Composition, and main mechanical properties of Ti-6Al-4V at room temperature.

Table 3. Machining parameters for experimental testing.

Table 4. Shear band chips microhardness profiles for flood $-150 \mathrm{~m} / \mathrm{min}, 1000 \mathrm{psi}-150 \mathrm{~m} / \mathrm{min}$ and $1000 \mathrm{psi}-250 \mathrm{~m} / \mathrm{min}$ with values highlighted for the points located near the tool-chip interface. 


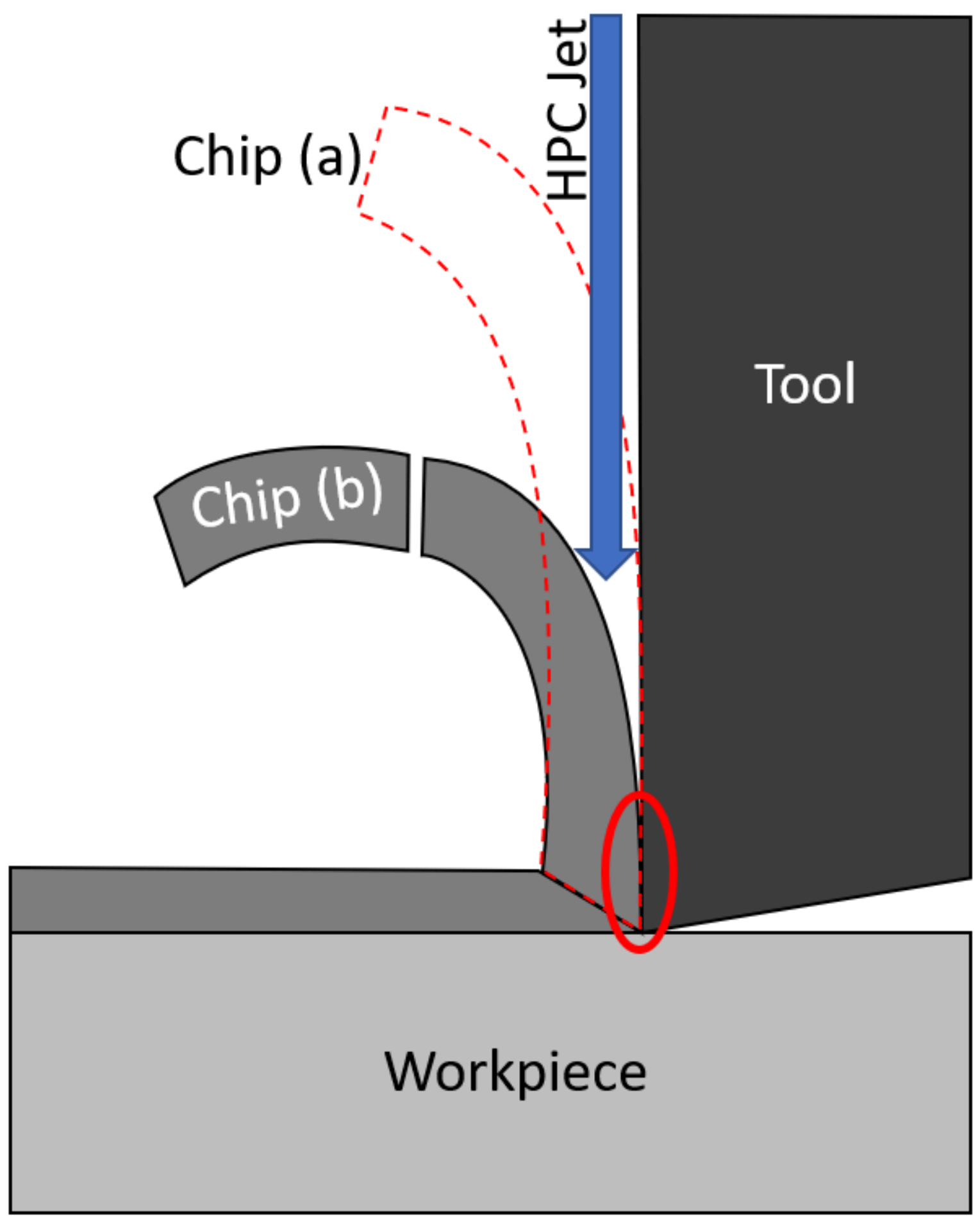

Fig. 1. - Graphic representation highlighting the changes in chip formation and contact length between (a) flood/dry and (b) HPC conditions. 


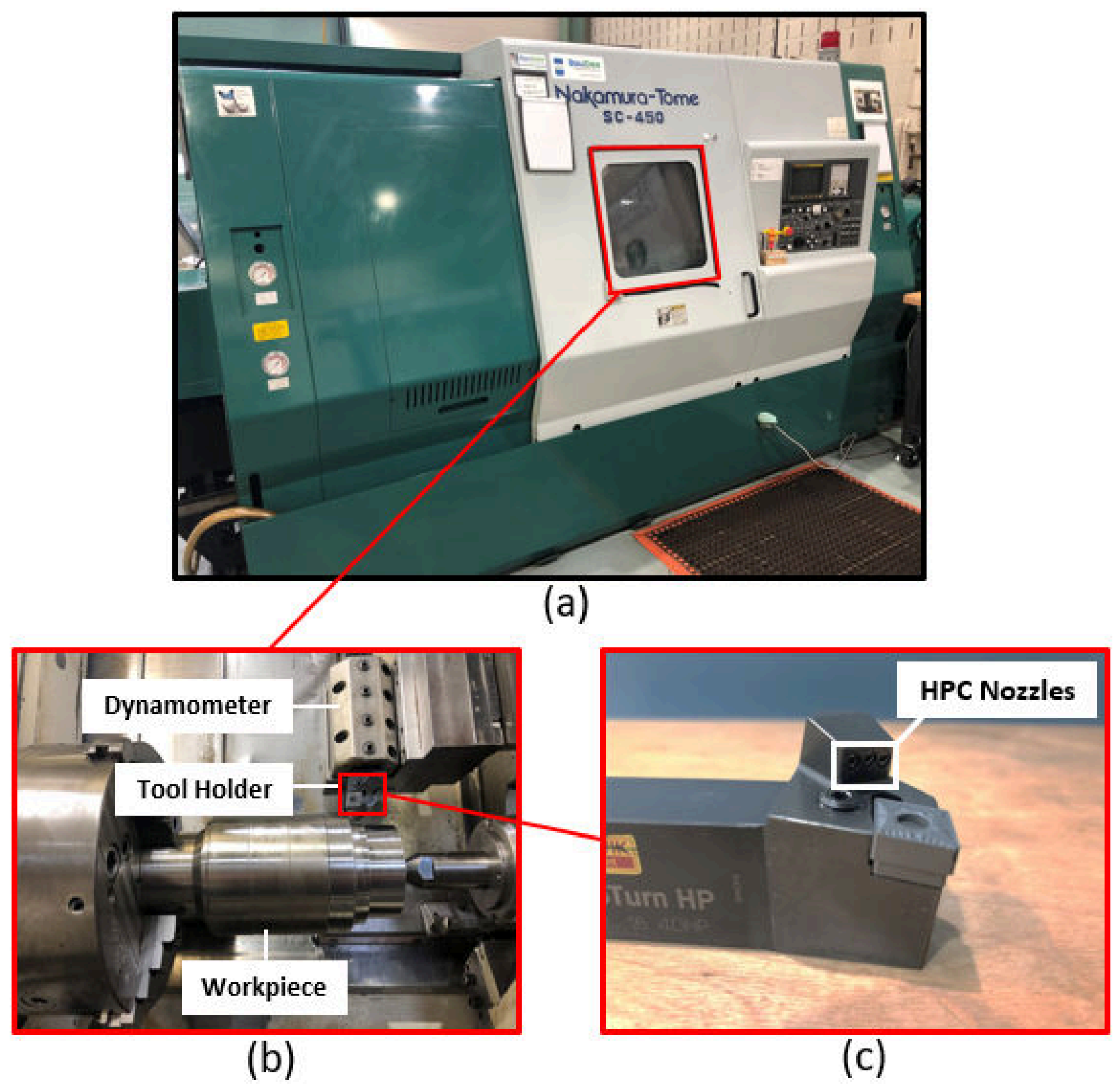

Fig. 2. - (a) Machine tool, (b) workpiece, dynamometer, tool holder setup and (c) detailed view of tool and coolant-through tool holder. 


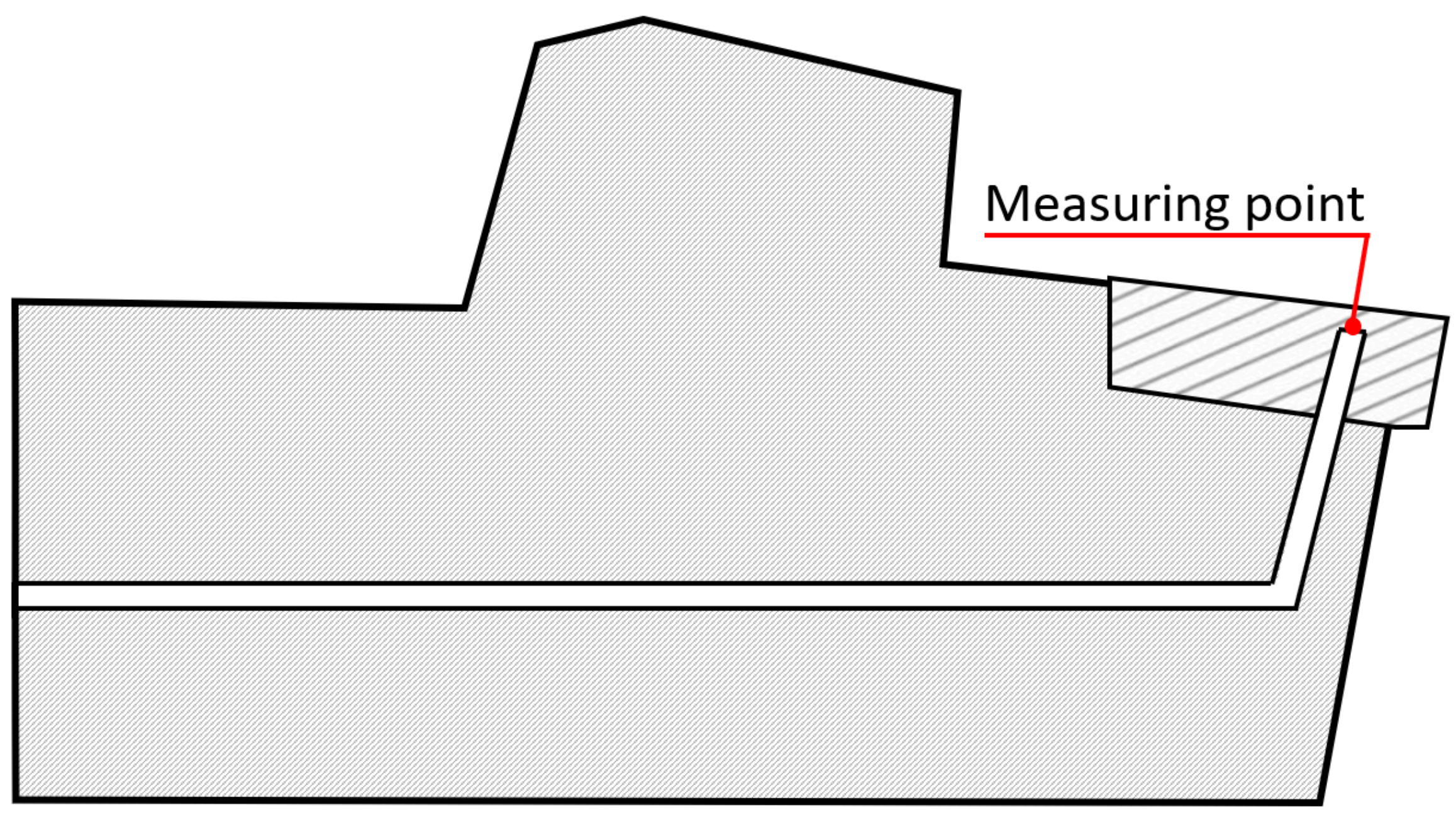

Fig. 3. - Experimental temperature measurement point. 

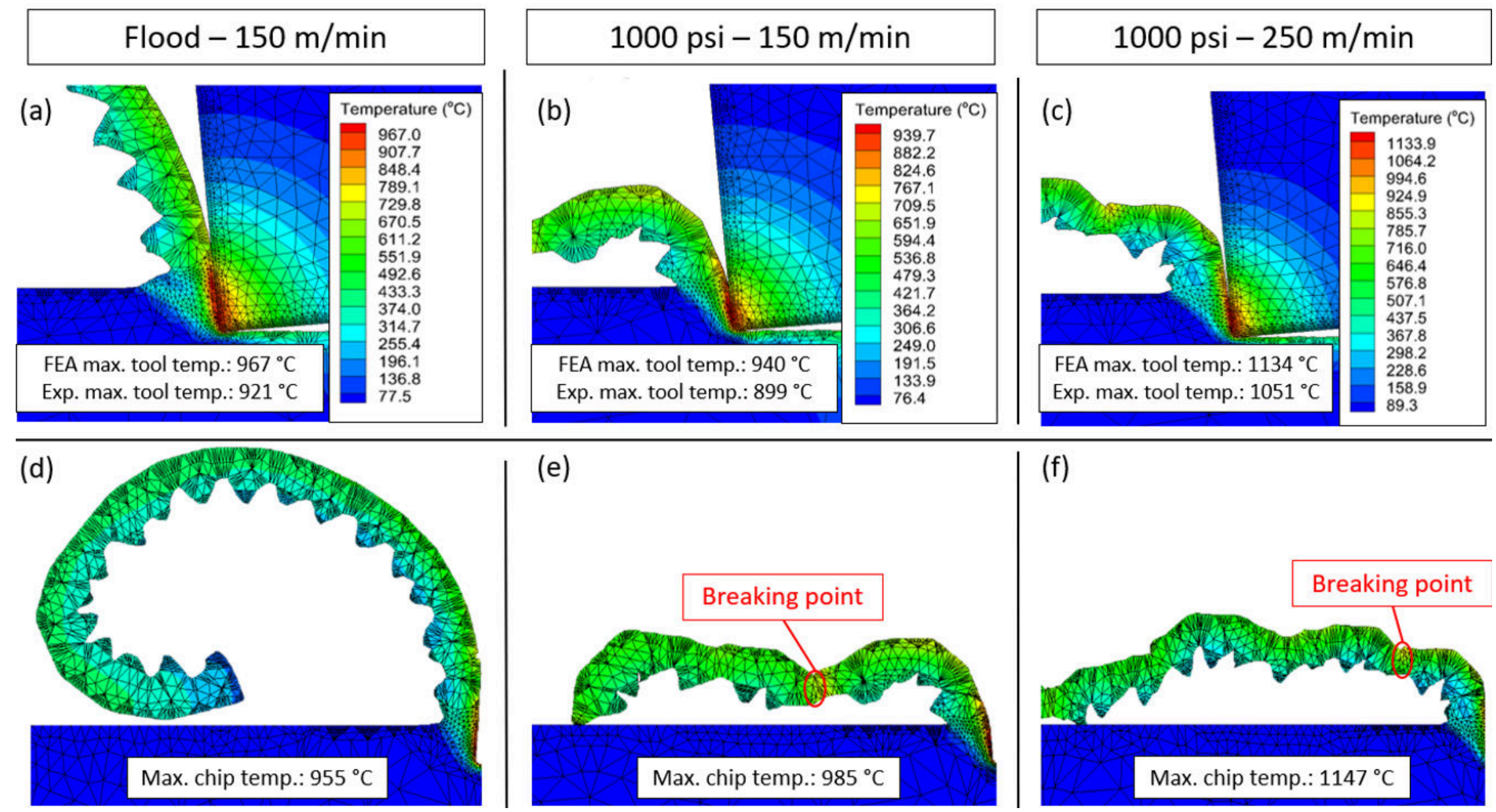

Fig. 4. - Temperature measurements for both simulation and experimental conditions, combined with FEA results for chip formation at (a,d) flood - $150 \mathrm{~m} / \mathrm{min}$, (b,e) $1000 \mathrm{psi}-150 \mathrm{~m} / \mathrm{min}$ and (c,f) $1000 \mathrm{psi}-250 \mathrm{~m} / \mathrm{min}$. 


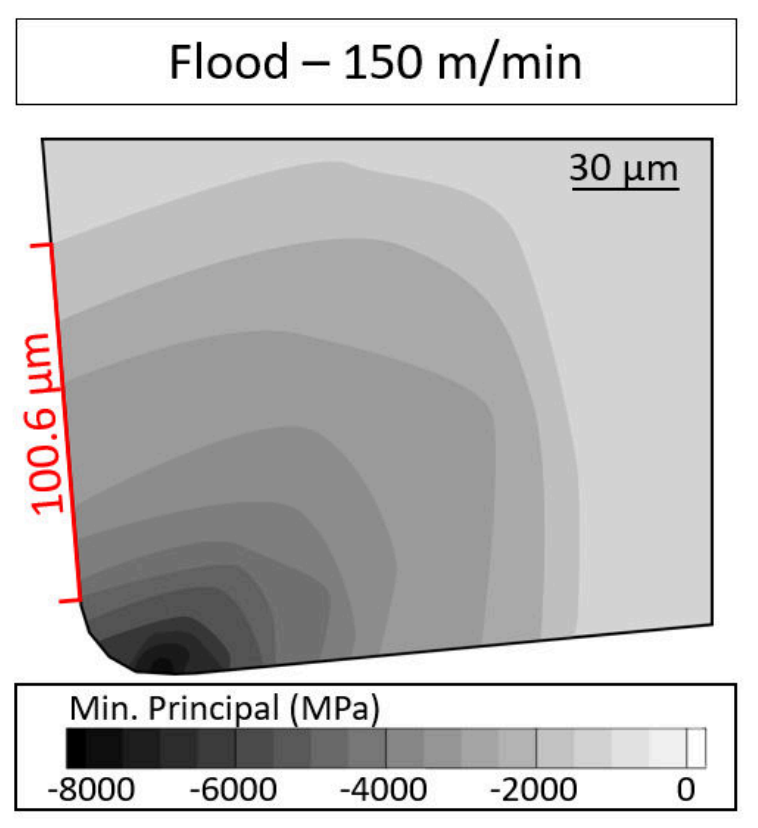

(a)

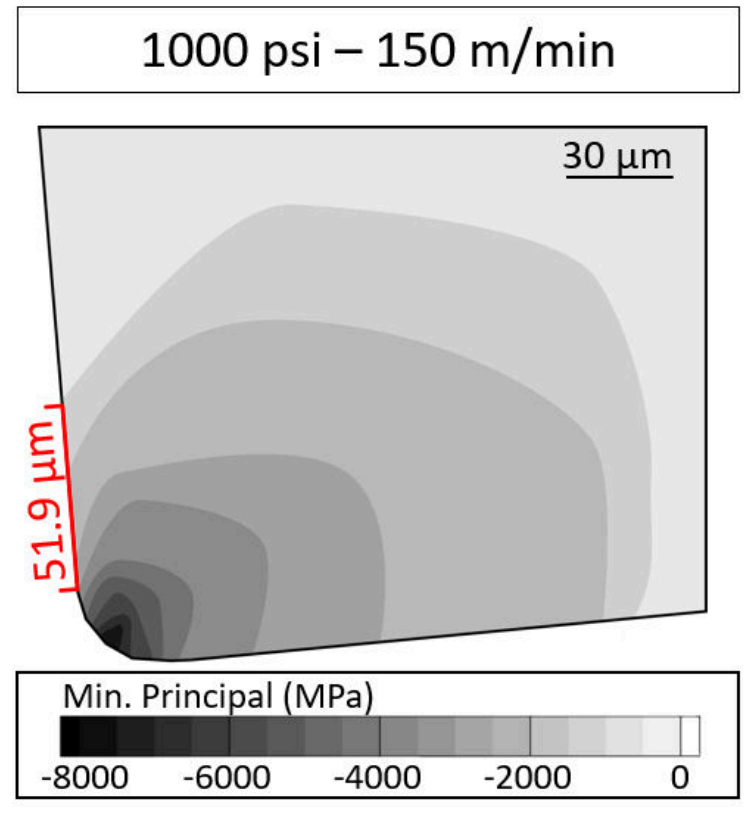

(b)

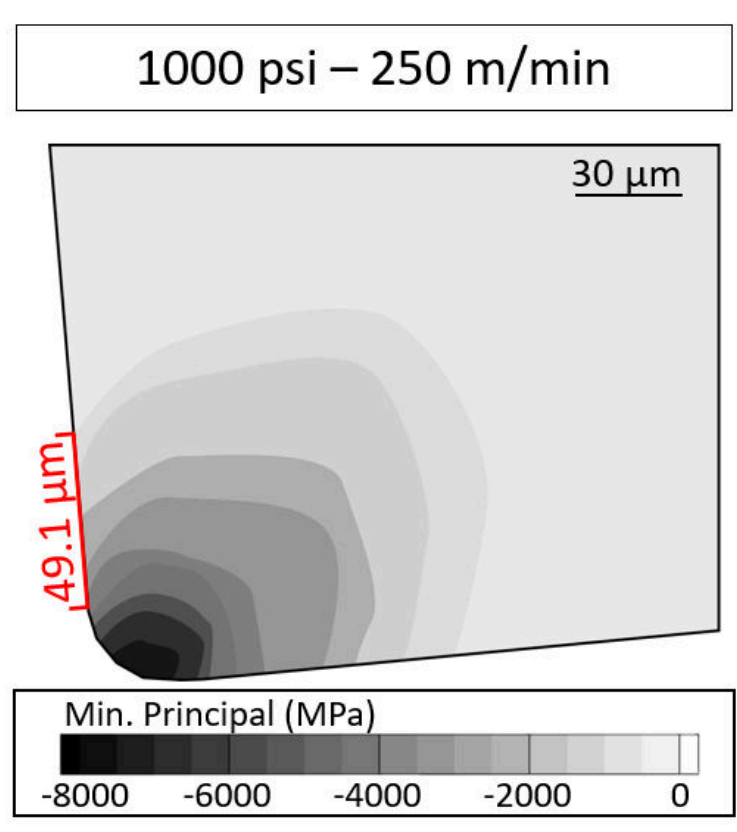

(c)

Fig. 5. - Tool stress profiles and TCCL for (a) flood - $150 \mathrm{~m} / \mathrm{min}$, (b) $1000 \mathrm{psi}-150 \mathrm{~m} / \mathrm{min}$ and (c) $1000 \mathrm{psi}-250 \mathrm{~m} / \mathrm{min}$. 


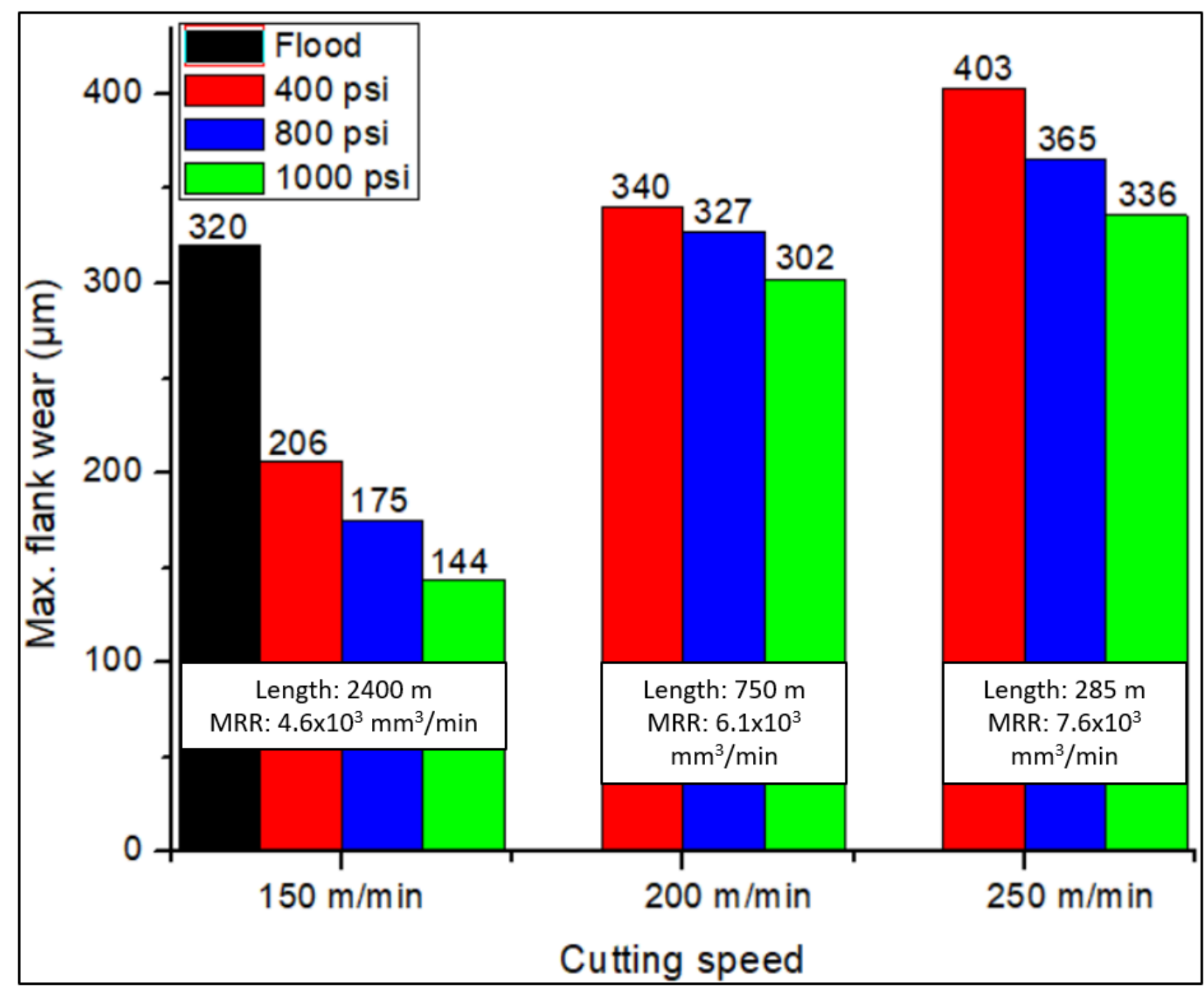

Fig. 6. - Flank wear comparison chart + MRR (Material Removal Rates) for all conditions. 


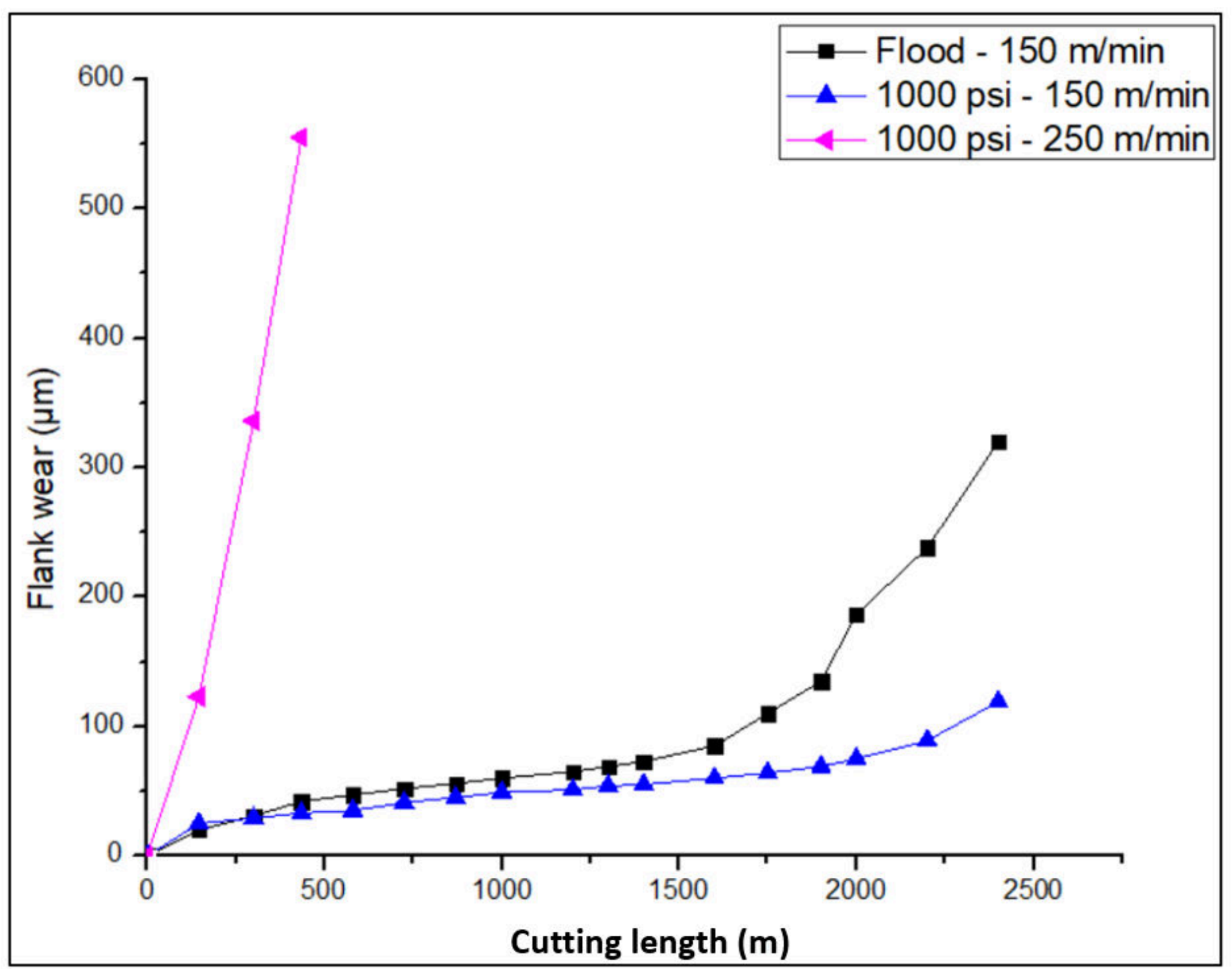

Fig. 7. - Tool wear progression curves for flood - $150 \mathrm{~m} / \mathrm{min}, 1000 \mathrm{psi}-150 \mathrm{~m} / \mathrm{min}$ and $1000 \mathrm{psi}-250 \mathrm{~m} / \mathrm{min}$. 


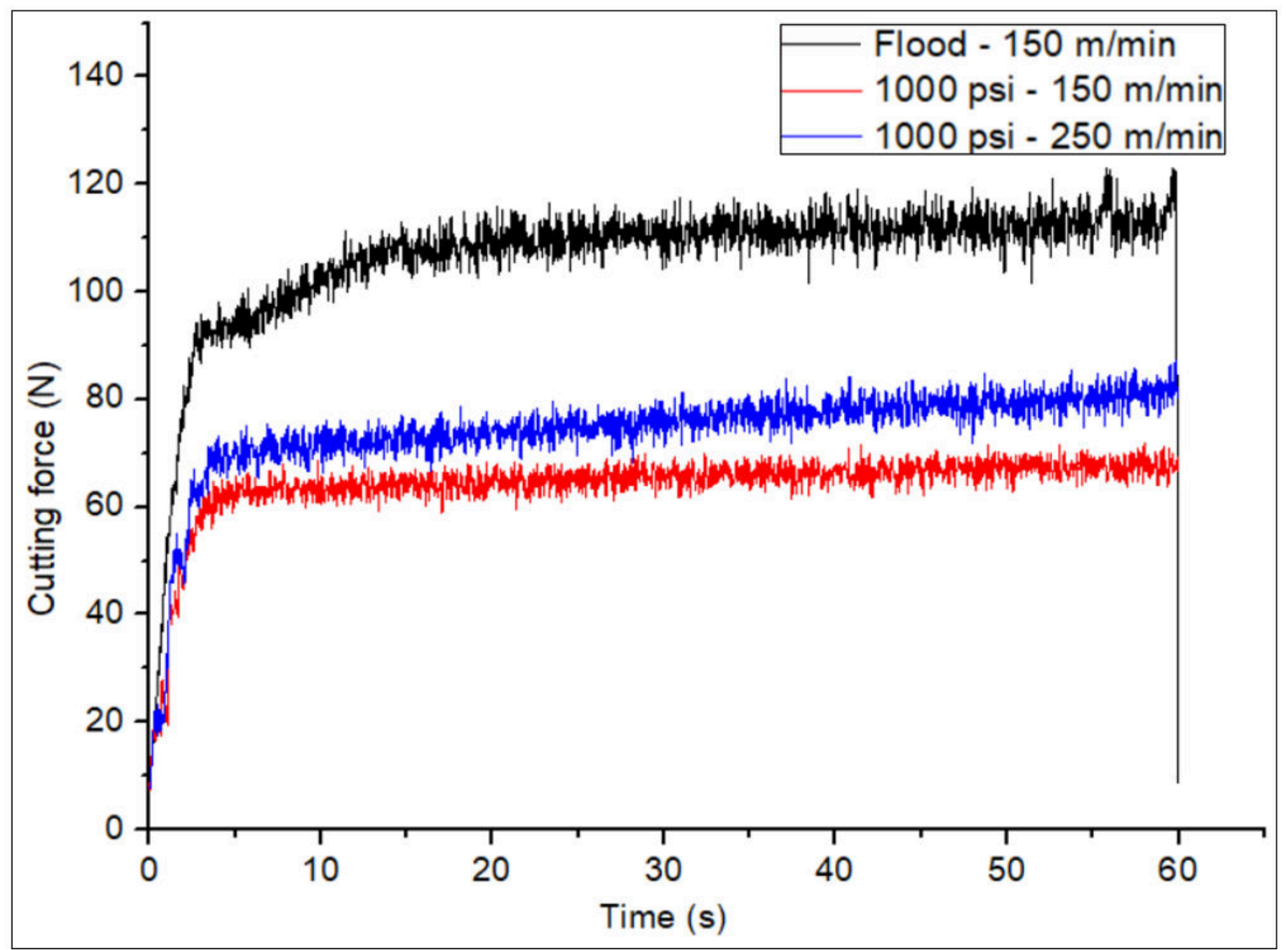

Fig. 8. - Cutting forces for flood - $150 \mathrm{~m} / \mathrm{min}, 1000 \mathrm{psi}-150 \mathrm{~m} / \mathrm{min}$ and $1000 \mathrm{psi}-250 \mathrm{~m} / \mathrm{min}$. 

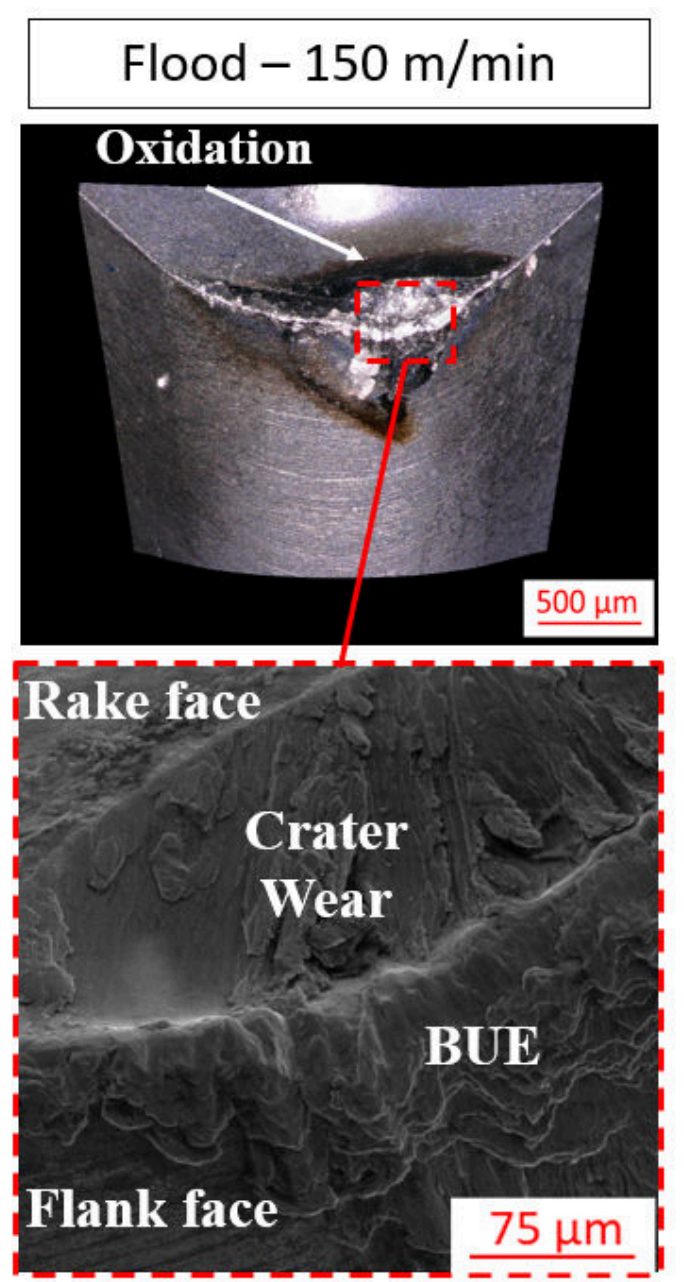

(a)
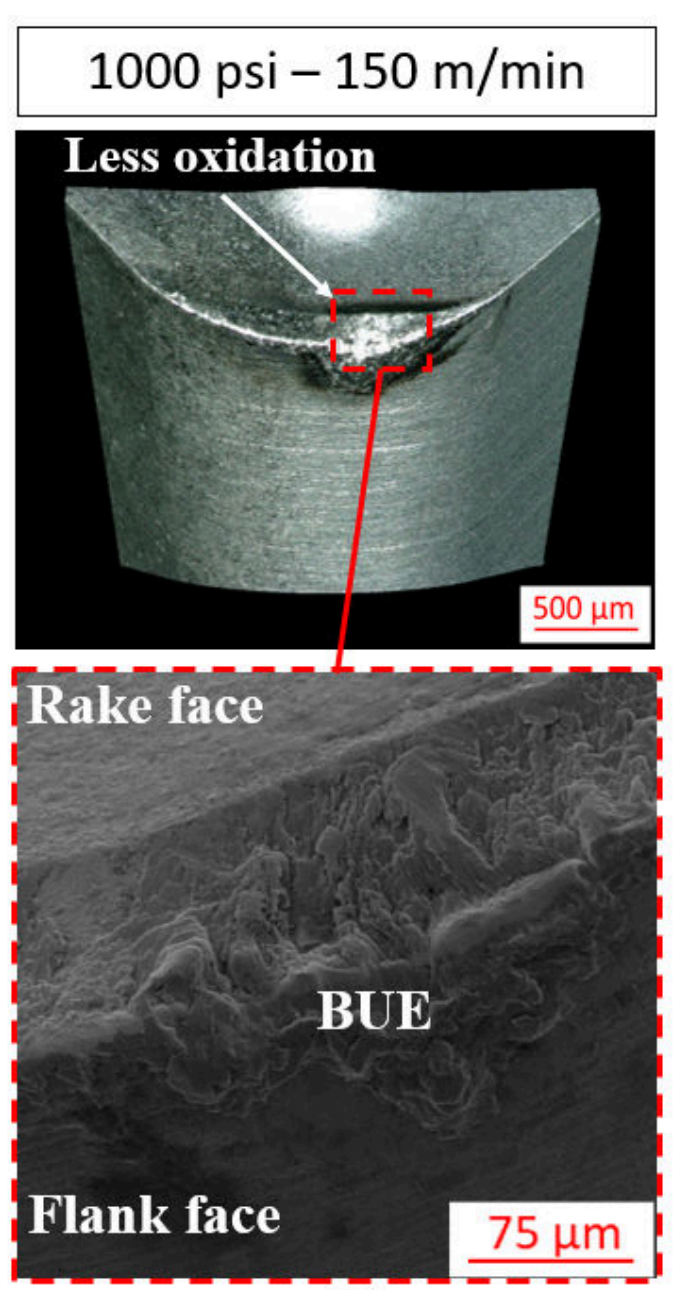

(b)
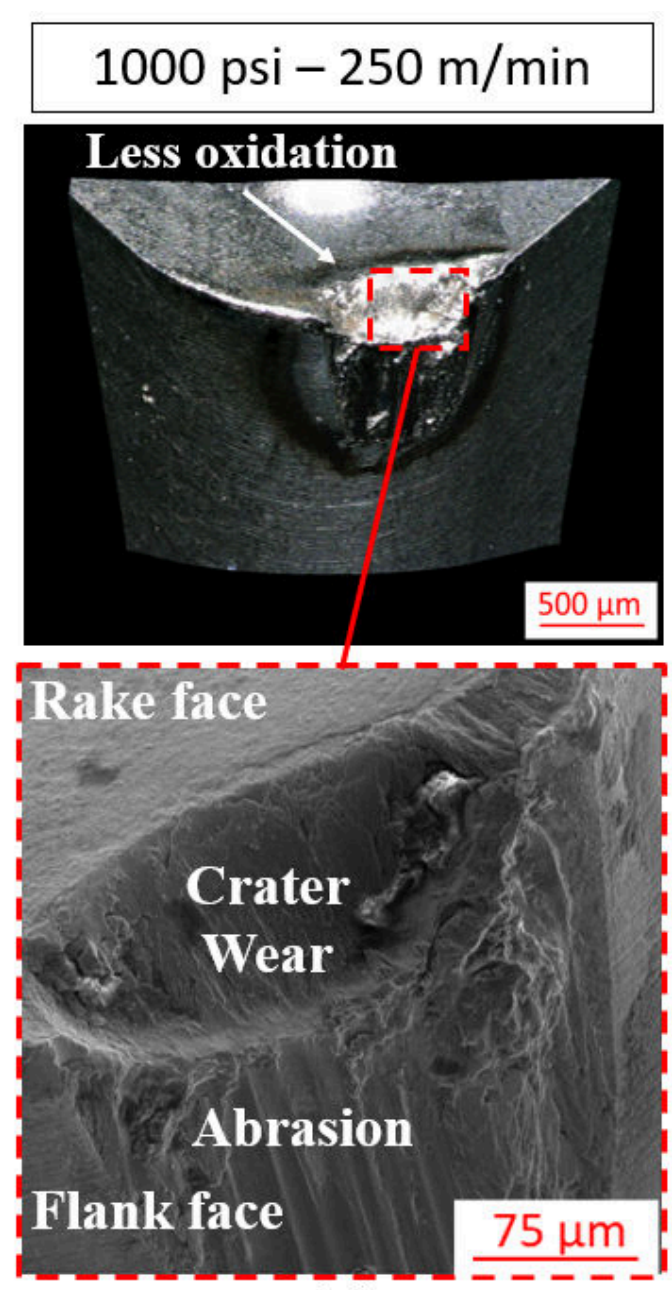

(c)

Fig. 9. - SEM of worn inserts for (a) flood - $150 \mathrm{~m} / \mathrm{min}$, (b) $1000 \mathrm{psi}-150 \mathrm{~m} / \mathrm{min}$ and (c) $1000 \mathrm{psi}-250 \mathrm{~m} / \mathrm{min}$, indicating the presence of oxidation, crater, BUE and flank wear modes. 


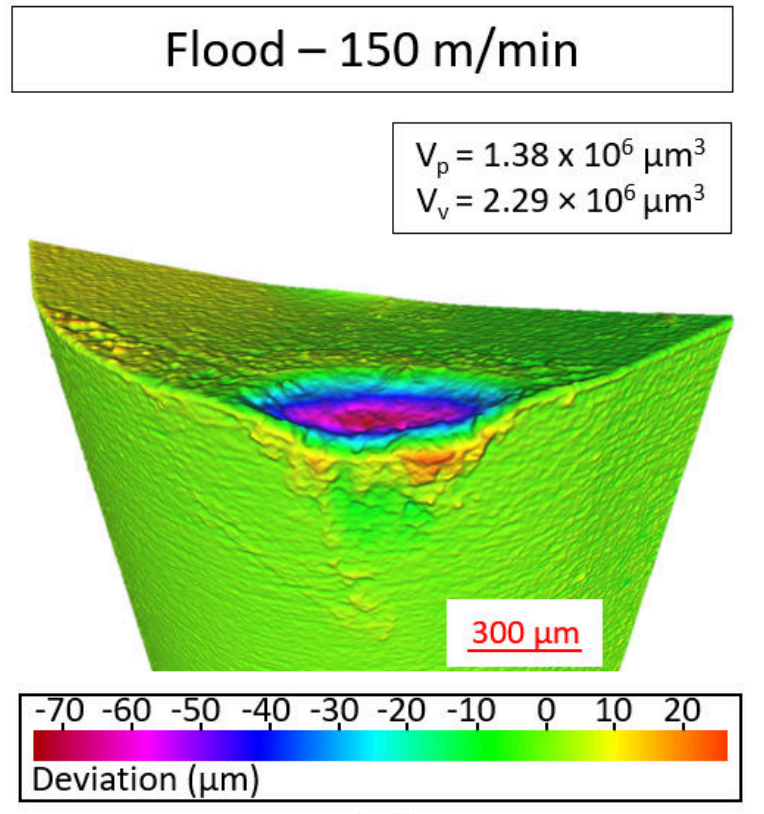

(a)

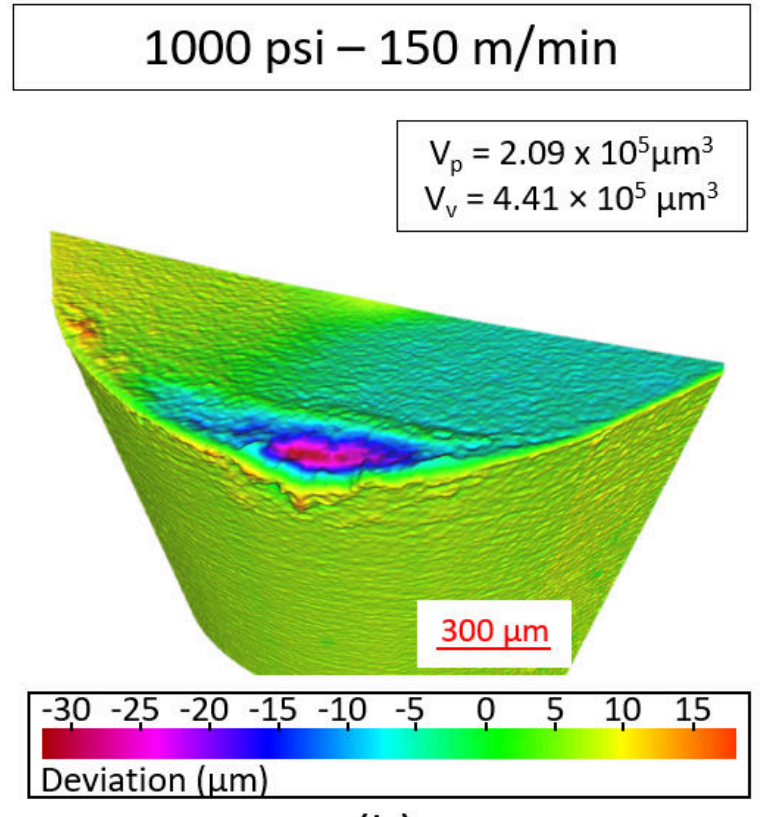

(b)

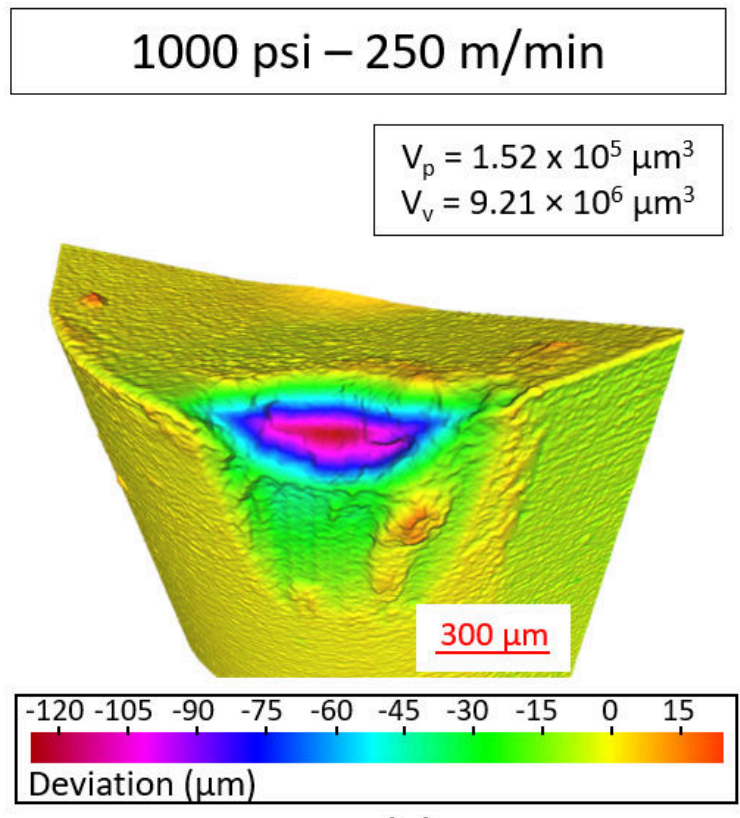

(c)

Fig. 10. - Volumetric analysis of worn tools for (a) flood - $150 \mathrm{~m} / \mathrm{min}$, (b) $1000 \mathrm{psi}-150 \mathrm{~m} / \mathrm{min}$ and (c) $1000 \mathrm{psi}-250 \mathrm{~m} / \mathrm{min}$, indicating the volumes of adhered and removed material from the cutting inserts. 
Flood $-150 \mathrm{~m} / \mathrm{min}$

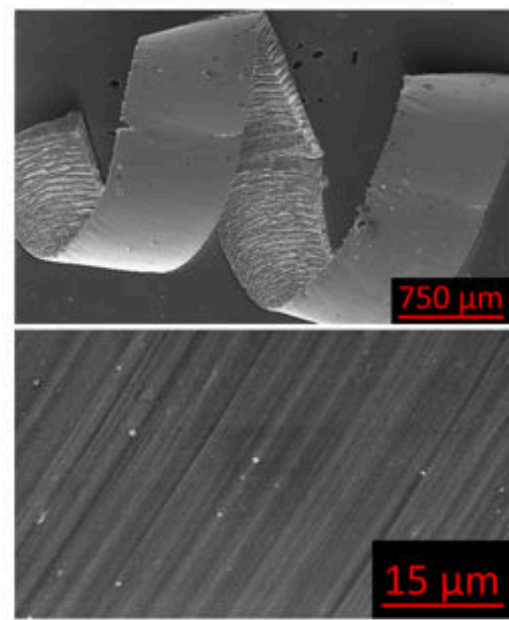

(b)

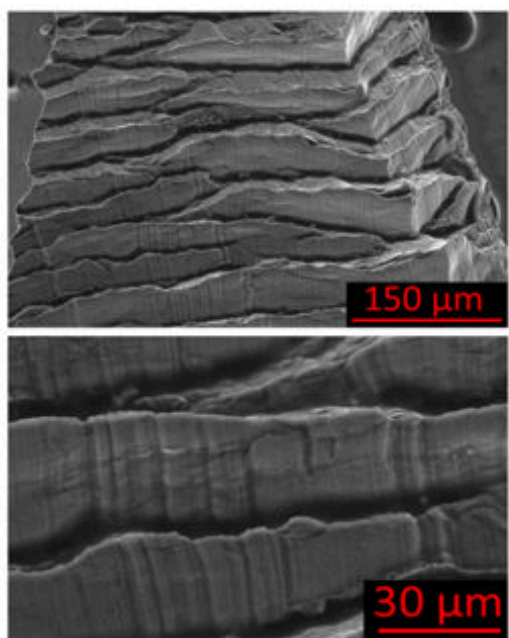

$$
1000 \mathrm{Psi}-150 \mathrm{~m} / \mathrm{min}
$$
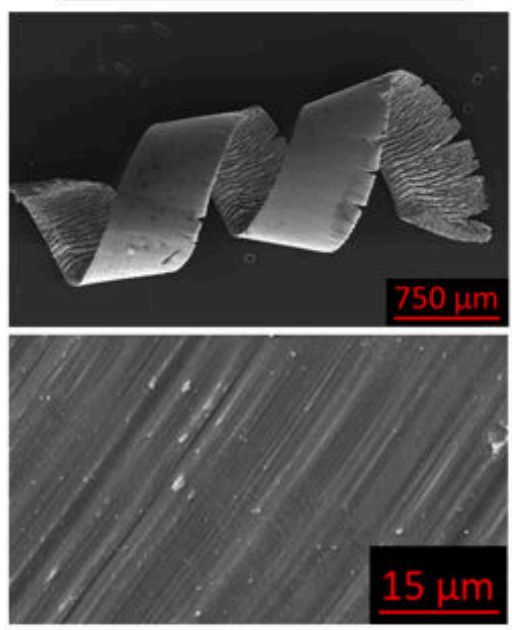

$15 \mu \mathrm{m}$
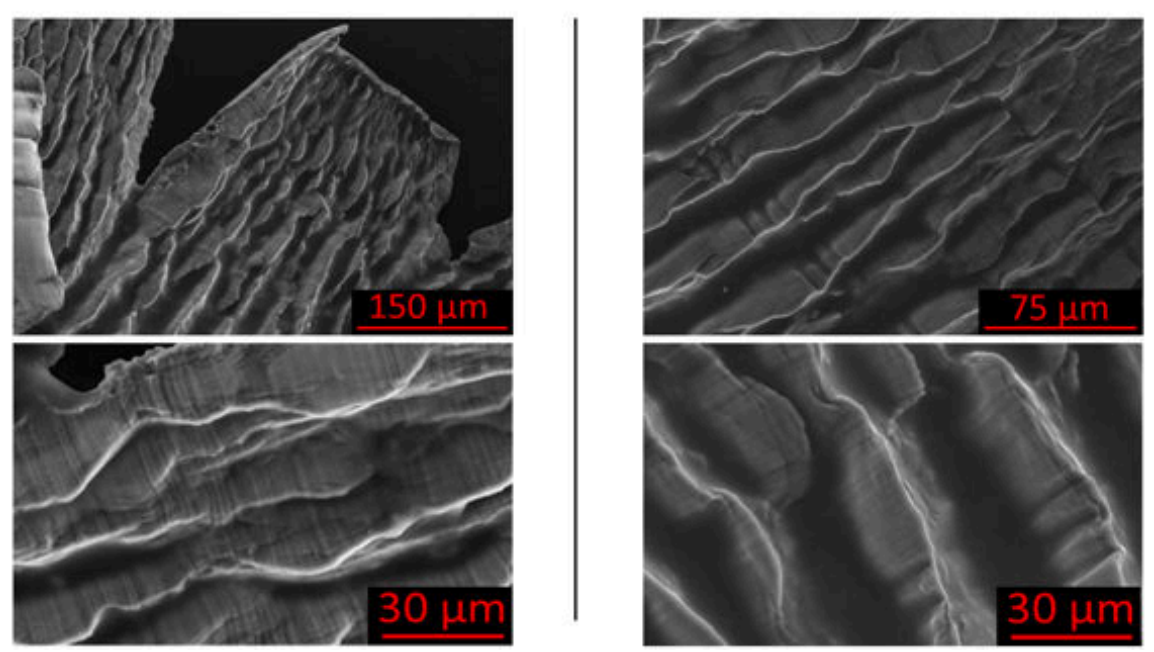

Fig. 11. - SEM of (a) chip undersurfaces and (b) shear bands. 

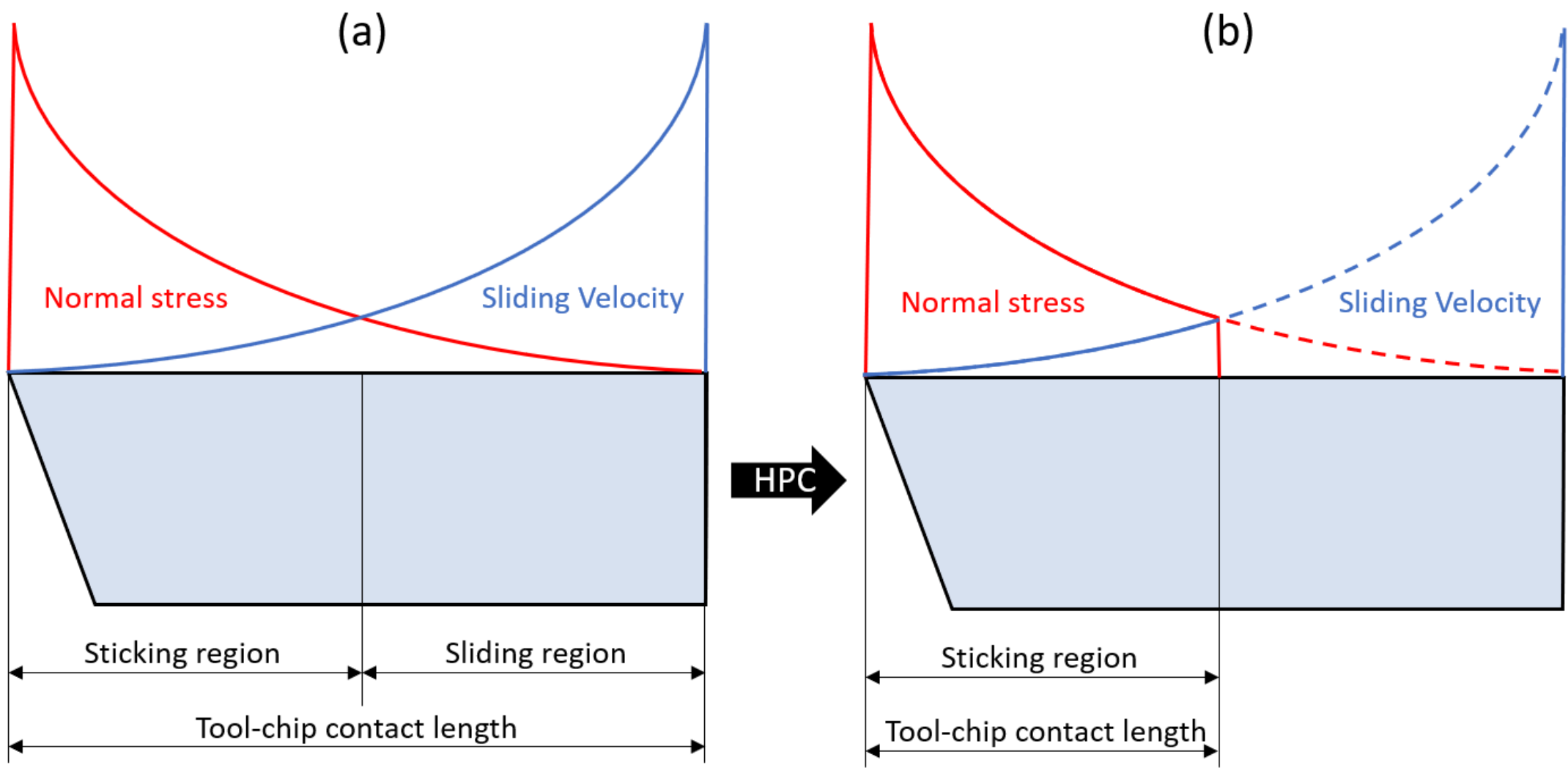

Fig. 12. - Tribological conditions along the rake face of the insert for (a) dry / flood, and (b) high-pressure coolant conditions. 


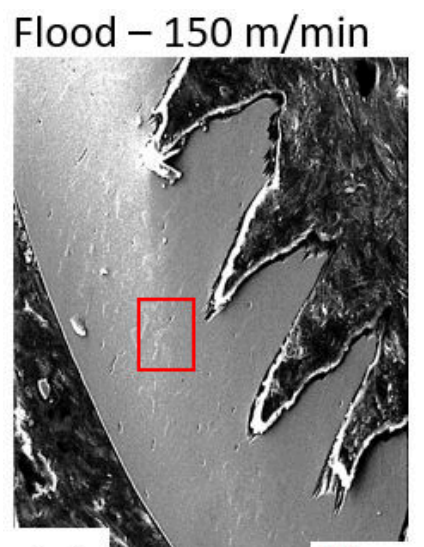

(a)

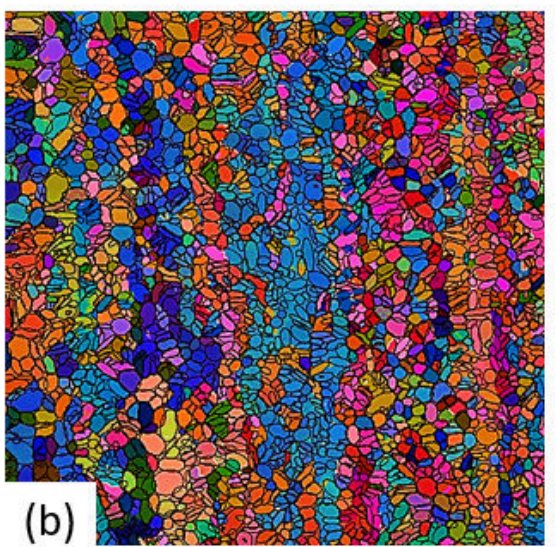

$1000 \mathrm{psi}-150 \mathrm{~m} / \mathrm{min}$
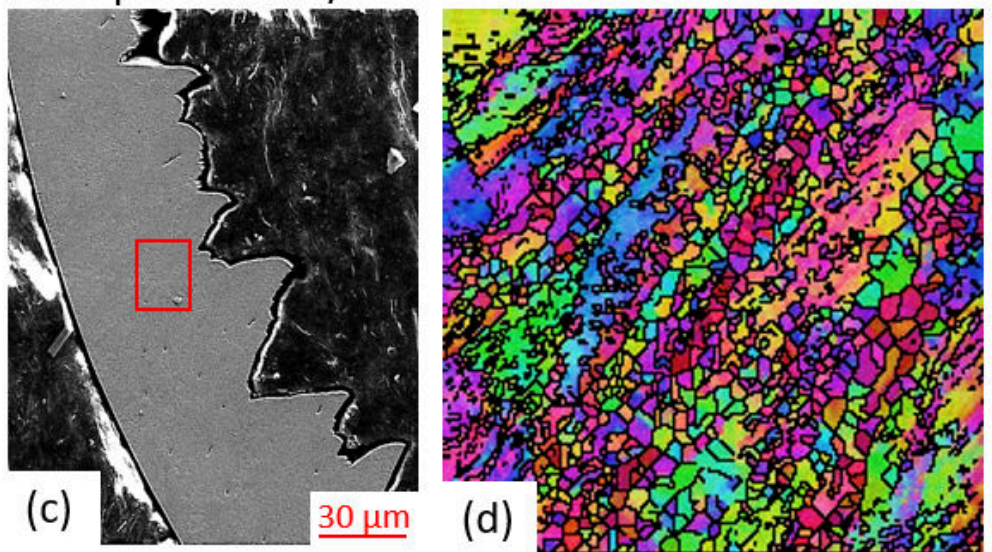

$1000 \mathrm{psi}-250 \mathrm{~m} / \mathrm{min}$
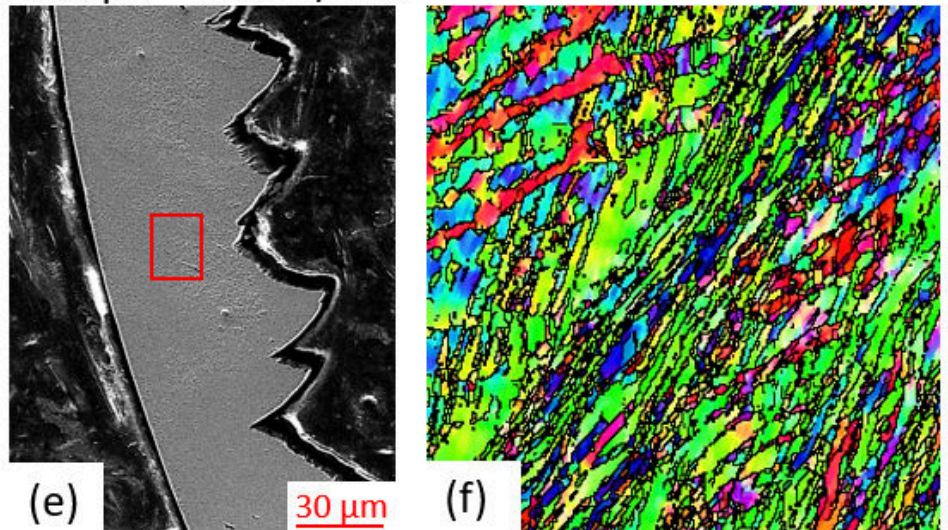

Fig. 13. - Chips cross-sections and EBSD orientation maps for (a,b) flood - $150 \mathrm{~m} / \mathrm{min},(\mathrm{c}, \mathrm{d}) 1000 \mathrm{psi}-150 \mathrm{~m} / \mathrm{min}$ and (e,f) $1000 \mathrm{psi}$ $-250 \mathrm{~m} / \mathrm{min}$ 
a)
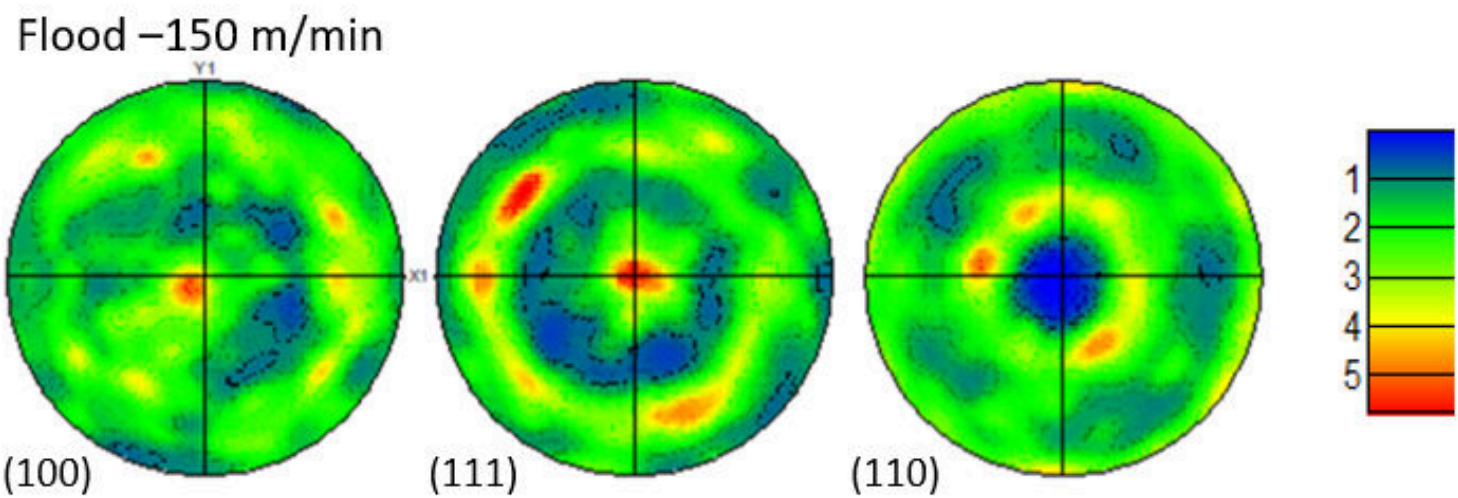

b)

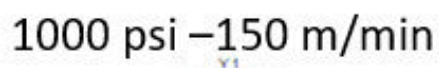

c)
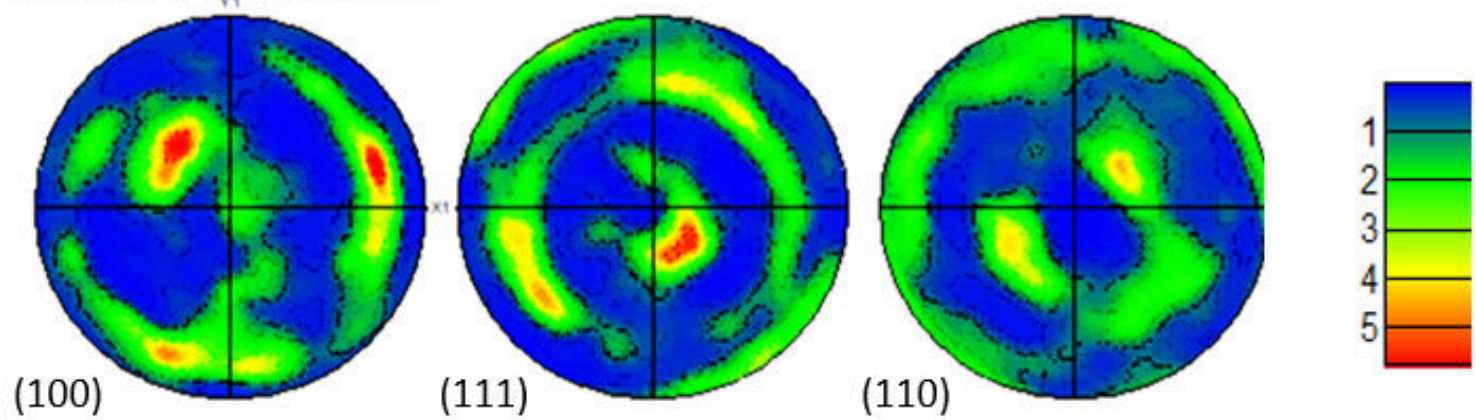

1000 psi -250 m/min

(100)
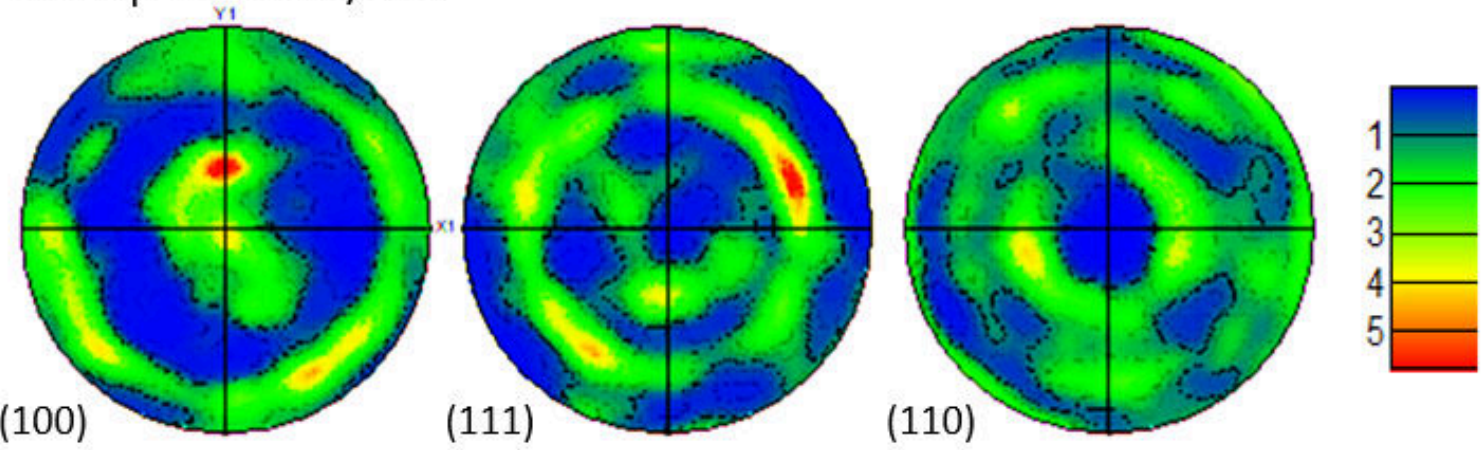

Fig. 14. - EBSD pole figures for (a) flood - $150 \mathrm{~m} / \mathrm{min}$, (b) $1000 \mathrm{psi}-150 \mathrm{~m} / \mathrm{min}$ and (c) 1000 $\mathrm{psi}-250 \mathrm{~m} / \mathrm{min}$. 
Table 1. Simulation parameters for all the tested conditions.

\begin{tabular}{lc}
\hline Minimum element size $(\mathbf{m m})$ & 0.02 \\
\hline Maximum element size & 0.1 \\
\hline Maximum number of nodes & 24000 \\
\hline No. of output frames & 30 \\
\hline Initial room temperature $\left({ }^{\circ} \mathbf{C}\right)$ & 20 \\
\hline Coolant heat transfer coefficient $\left(\mathbf{W} / \mathbf{m}^{2} \mathbf{K}\right)$ & $1 \times 10^{4}$ \\
\hline
\end{tabular}


Table 2. Chemical Composition, and main mechanical properties of Ti-6Al-4V at room temperature.

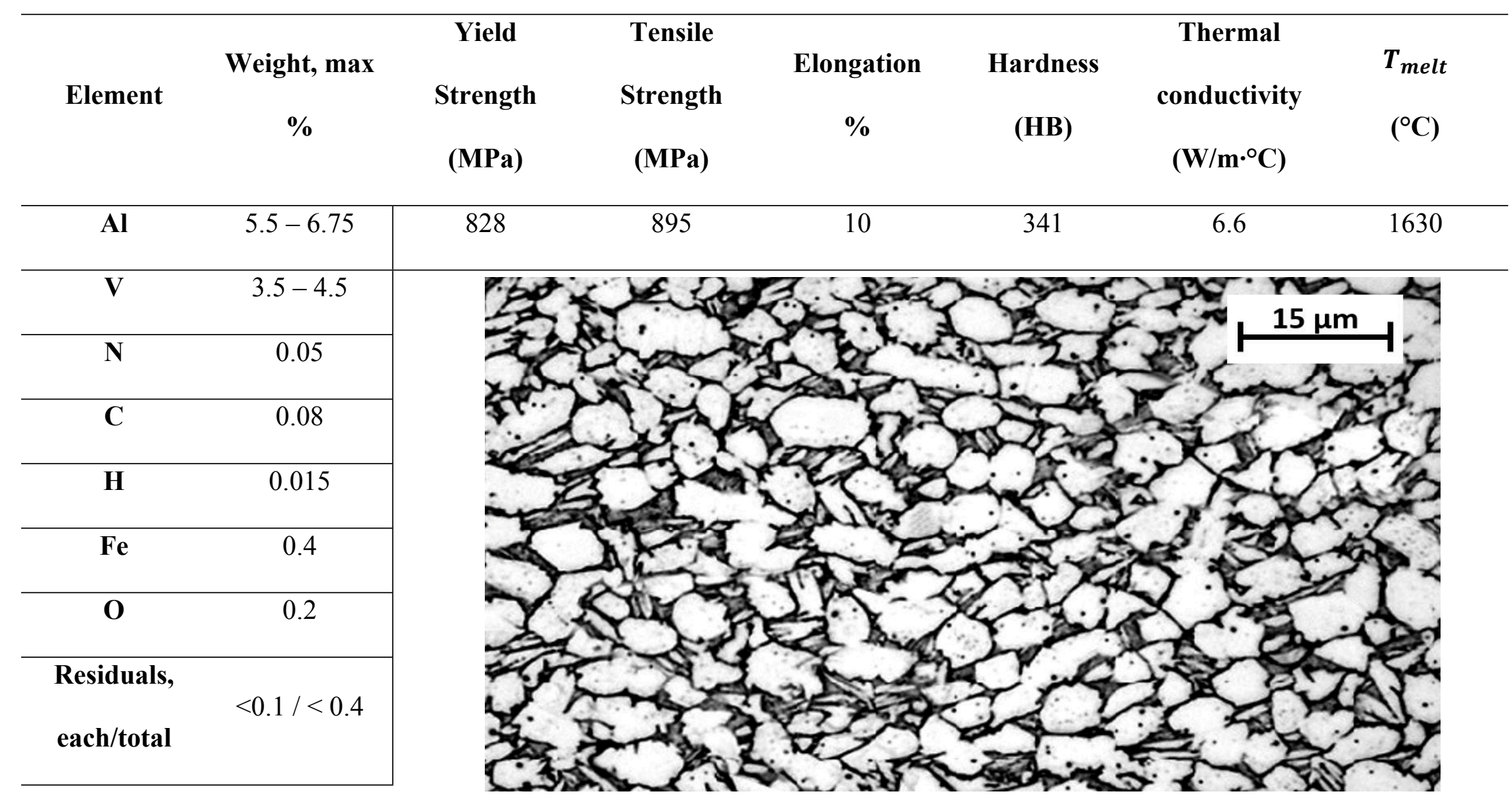


Table 3. Machining parameters for experimental testing.

\begin{tabular}{|l|c|c|c|c|c|c|}
\hline \multirow{2}{*}{} & \multicolumn{3}{|c|}{ Coolant pressure (psi) } & \multicolumn{2}{c|}{} \\
\cline { 2 - 6 } & $\begin{array}{c}\text { Flood } \\
\text { (Benchmark) }\end{array}$ & 400 & 800 & 1000 & $\begin{array}{c}\text { Feed } \\
\text { (mm/rev. })\end{array}$ & $\begin{array}{c}\text { DOC } \\
(\mathrm{mm})\end{array}$ \\
\hline \multirow{2}{*}{$\begin{array}{l}\text { Vc } \\
(\mathrm{m} / \mathrm{min})\end{array}$} & $\mathrm{n} / \mathrm{a}$ & \multicolumn{2}{|c|}{200} & \multirow{2}{*}{0.1225} & 0.25 \\
\cline { 2 - 4 } & $\mathrm{n} / \mathrm{a}$ & 250 & & \\
\hline
\end{tabular}


Table 4. Shear band chips microhardness profiles for flood - $150 \mathrm{~m} / \mathrm{min}, 1000 \mathrm{psi}-150 \mathrm{~m} / \mathrm{min}$ and $1000 \mathrm{psi}-250 \mathrm{~m} / \mathrm{min}$ with values highlighted for the points located near the tool-chip interface.

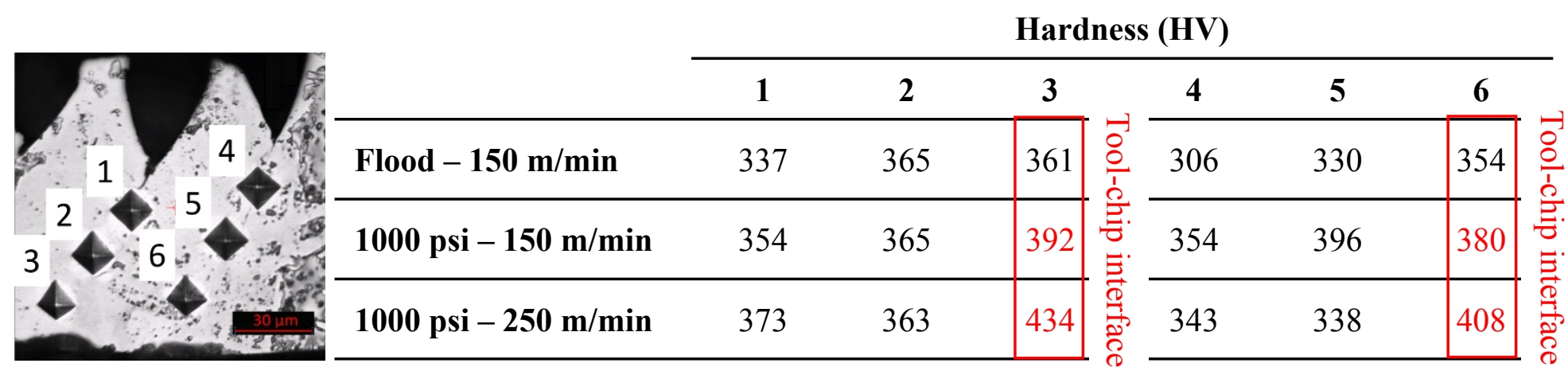




\section{Research highlights}

- Oxidation wear is reduced by the application of HPC.

- An increase in the heat generation by plastic deformation for the HPC condition.

- Coolant pressure and maximum flank wear are inversely proportional to each other.

- The chip formation process is facilitated by the application of HPC.

- Chips are strain hardened with the application of HPC. 


\title{
The role of high-pressure coolant in the wear characteristics of WC-Co tools during the cutting of Ti-6Al-4V
}

\author{
Stolf, Pietro
}

Elsevier

Stolf P, Paiva JM, Ahmed YS, et al., (2019) The role of high-pressure coolant in the wear characteristics of WC-Co tools during the cutting of Ti-6Al-4V. Wear, Volumes 440-441,

December 2019, Article number 203090

https://doi.org/10.1016/j.wear.2019.203090

Downloaded from Cranfield Library Services E-Repository 